\title{
Stage duration estimation for Calanus populations, a modelling study
}

\author{
Charles B. Miller ${ }^{1}$, Kurt S. Tande ${ }^{2}$ \\ ${ }^{1}$ College of Oceanic and Atmospheric Sciences, Oregon State University, Corvallis, Oregon 97331-5503, USA \\ ${ }^{2}$ Norwegian College of Fishery Sciences, University of Tromsø, N-9037 Tromsø, Norway
}

\begin{abstract}
Population dynamics of Calanus finmarchicus have been modelled using very finely divided representation of the stock according to age-within-stage, in the manner of models developed by C. S. Davis, A. Sciandra, F. Carlotti and others. A key assumption of the model is that development rate is relatively insensitive to food-limitation, so that stage duration can be represented by a temperature function alone. We used the Belehrádek function for this purpose, noting that better data are needed for fitting its parameters. The model closely simulates the timing of stage progression and relative stage abundances of $C$. finmarchicus in the Malangen fjord system (northern Norway) during the winter-spring generation. The model is sensitive to the resolution of the age-within-stage division, but it is fully stable at $0.5 \mathrm{~h}$ increments. Modifications of the model simulated several methods for field estimation of stage duration in Calanus (or other highly seasonal copepod populations). A method based on changes in stage proportions (the 'Heinle graph' method) is biased by confounding of the effects of developmental progress and mortality on stage proportions. However, the model shows that the bias is mild and the method gives useful estimates of stage duration. Simulation of a method based on molting rate determinations ('Kimmerer experiments') showed its unsuitability for highly seasonal stocks in which stage composition is changing rapidly. Differences in C. finmarchicus survivorship schedules between constant and continuously increasing temperatures were simulated, showing that such differences in pattern are critical to annual survival and stock production. Simple methods for fitting mortality rates to data using the model were extremely sensitive to sampling noise. More complex methods may succeed but remain to be developed.
\end{abstract}

KEY WORDS: Calanus Population model $\cdot$ Stage duration

\section{INTRODUCTION}

International planning is in progress for intensive studies of the population biology of marine zooplankton. In particular, the U.S.-initiated GLOBEC program has begun a several-year study of the dominant winter-breeding copepods of Georges Bank and the Gulf of Maine, USA. These are Calanus finmarchicus and several species of Pseudocalanus (U.S. GLOBEC 1992). The goal is to understand the effects of physical habitat factors on the transfer of nutrition through these copepod populations to stocks of commercially important fish species, particularly cod Gadus morhua and haddock Melanogrammus aeglefinus. Direct feeding by these fish on copepods occurs mostly as larvae eating nauplii (Kane 1984, Buckley \& Lough 1987). Therefore, estimation of naupliar numbers and explanation of observed variability will be important to the study. Knowledge of the overall dynamics of the copepod populations will be useful for explaining the response of both copepods and their fish predators to variations in marine climatic conditions. Long-term studies of $C$. finmarchicus in Norwegian waters during both the PRO MARE and the ongoing MARE NOR programs underscore the importance of this species in high latitude waters (Tande 1991, Tande \& Slagstad 1992).

The dynamics of copepod populations are obscured by great variability in estimates of their numbers. However, if approximately the same progression of 
stages is occurring over a reasonably broad stretch of ocean, then it may be possible to derive considerable information about development rates, growth rates, and survivorship from recurring evaluations of stage proportions and body sizes and from time series of field experiments on egg production and molting rates. We have conducted a series of modelling studies intended to show some of the possibilities and limitations of these methods as applied to Calanus finmarchicus. The input and verification data for these models come primarily from work in Norwegian fjords, but the implications should apply generally. They lead us to some recommendations for the work on the $C$. finmarchicus stock of Georges Bank and for study of calanid populations everywhere.

Our models follow in some ways that of Carlotti \& Sciandra (1989) and Carlotti \& Nival (1992) which was developed to describe population cycles in Euterpina. Models with similar features were presented earlier by Davis (1984) and Sciandra (1986). The key feature of these models is division of each stage into a number of age steps, with the probability of advance to the next stage increasing from zero only after a minimal stage duration has passed, then rising to 1.0 over an interval mimicking a known or reasonable variability in stage duration. This provides models that are very well behaved with respect to development timing compared to vectorial population models with one abundance element per stage and a single probability of stage advance at each time step (Caswell 1989). Such transition matrix models suffer from unavoidable (and unrealistic) numerical dispersion, so we have abandoned them at the cost of the elegant methods they provide for estimation of stock increase parameters.

We have used our age-within-stage models to study the expectations and biases of stage duration estimates based on (1) recurring estimates of stage proportions and on (2) molting rate experiments as described by Kimmerer \& McKinnon (1987) and Peterson et al. (1991). Work with the model showed that the most important parameters for modelling Calanus population processes describe the initial, winter spawning pattern, that is, the timing of egg input as the model starts. Data for this can be derived from a suitable time series of egg production estimates (e.g. Diel \& Tande 1992). We show some of the implications of the form of this spawning function for stage duration estimates and molting rate experiments. Models of the age-within-stage type can be combined with appropriate field data to approximate survivorship patterns and population production. We spell out the necessary data and discuss the problems of fitting the model and extraction of desired estimates.

\section{LIFE HISTORY AND GROWTH PATTERNS OF CALANUS FINMARCHICUS}

Calanus finmarchicus stocks spend the late summer and autumn periods in a prolonged diapause that occurs in the fifth copepodite stage (C5). During this rest phase they are deep in the water column, mostly quiescent (although alert and capable of rapid escape responses), and not feeding. Arousal occurs in early to mid-winter, followed by a final molt to the adult stage. Males precede females on average and are avajlable for mating as the females appear. Females (generation $G_{0}$ in terminology attributable to Ian McLaren) move upward in the water column and begin to spawn (producing $\mathrm{G}_{1}$ ) when abundant food becomes available during the spring increase in phytoplankton. Eggs hatch as nauplii, and there is a progression of 6 naupliar then 5 copepodite stages before return to diapause at depth. In many places there is more than one generation, with the $G_{2}$, $\mathrm{G}_{3}$, or even later generations finally entering diapause in late summer. This does not happen in Norwegian fjords (Tande 1991), and it appears that the $G_{2}$ generation started by maturation of a fraction of $\mathrm{G}_{1}$ over the Nova Scotian shelf (McLaren \& Corkett 1986) and in shelf water off New England (Miller et al. 1991) never reaches late copepodite stages and probably does not contribute to the following year's stock.

Some uncertainty remains about the relative importance of temperature and food availability in determining the rates of growth and development in calanoid copepods. McLaren (1978) working with Marshall et al.'s (1934) data from Loch Striven has maintained that the timing of development of Calanus finmarchicus and Pseudocalanus spp. is the same in the field as in the laboratory at the same temperature and at full rations, showing therefore the absence of food limitation. Others have noted that size of individuals (Carlotti et al. 1993) and egg production vary strongly, and that at least egg production (Runge 1985, Nielsen \& Richardson 1989, Peterson et al. 1991) appears to be correlated with plant standing stocks as measured by chlorophyll concentration, implying definite food limitation. We contend, based mostly on Miller et al. (1984), that development, the progression from stage to stage, is much less sensitive to food limitation than is growth, the addition of new tissue mass, including egg production. Timing of the stage progression will be relatively insensitive to food availability above a fairly low threshold, while growth, and thus terminal size, will vary as food availability changes. We lack data with which to settle this issue with certainty.

Carlotti \& S. Nival (1992) and Carlotti et al. (1993) argue that molting from a given stage will depend upon achievement of a critical weight very close to the terminal weight for the stage. We contend, again 
based on the experiments reported by Miller et al. (1984), that hormonal signals for the next molt are received relatively early in each intermolt stage, surely before half of its duration at full nutrition, and that molting proceeds after those signals regardless of subsequently achieved weight. Thus, the physiology of molting tends to sustain the molting rate over a wide range of food availability. Again, the cost of proceeding with a relatively fixed molting schedule, regardless of achieved growth, is variable terminal size. E. G. Durbin \& A. G. Durbin (unpubl.) found a strong difference in development of Calanus finmarchicus between May 1988 and June 1989 in Great South Channel (Gulf of Maine). In the earlier year progress was at the maximum expected rates for the observed temperatures. In the latter year development slowed and essentially stopped in C4, almost certainly because of very reduced food supplies. Thus, food limitation of development clearly can occur in the field. We only claim that useful modelling results can be achieved by treating food limitation as an unusual circumstance. This allows us to develop our model very simply on the basis of a temperature function for stage duration taken from Corkett et al. (1986; see below).

\section{MODEL FORMULATION}

Modelled processes proceed as shown in Fig. 1, a flow diagram; symbols are defined in Table 1 . The model is based on recurring evaluation of a series of 12 $(j=1, \ldots, 12)$ pairs of vectors, one for each stage from egg through $\mathbf{C 5}$. Elements of $\mathbf{A}_{j}$ in each pair are the abundances of successive ages within the stage; elements of $\mathbf{D}_{j}$ represent the fraction of the stage duration completed. At each time step all $\mathbf{D}_{j, i}$ are incremented according to the fraction completed in that interval of the stage duration predicted by a modification of the Belehrádek function given by Corkett et al. (1986). This function is

$$
\text { Stage duration }(\mathrm{d})=a_{j}(\mathrm{~T}+10.6)^{-2.05} \text {, }
$$

where $a$, values are given in Table 2 . The values 10.6 and -2.05 are parameters fitted to a small set of rearing data. Extended study of Calanus finmarchicus populations should include preparation of a much more extensive stage duration data set. As shown in Table 2, we modified the fitted values of a, so as to approximate growth patterns for Calanus marshallae (Peterson 1986) and Calanus pacificus (Vidal 1981) which are better studied than that of $C$. finmarchicus. At each time step the conversion is $\mathbf{D}_{j, i}:=\mathbf{D}_{j, i}+1 /\left[a_{j}(\mathrm{~T}+\right.$ $10.6)^{-2.05}$ ], where $:=$ means 'replace' in the Pascal language sense. The units of $\mathbf{D}_{j, i}$ are $\mathrm{d}^{-1}$. A copepod living at temperature $\mathrm{T}$ will complete stage $j$ in $\boldsymbol{a}_{j}(\mathrm{~T}+$
$10.6)^{-2.05}$ days, so in $1 \mathrm{~d}$ it completes the fraction $1 /\left[a_{j}(T+10.6)^{-2.05}\right\}$ of its development toward the next molt. These fractions can be added for successive days (at varying temperatures) until the sum reaches $1 .$, when molting occurs to stage $j+1$. Thus, $\mathbf{D}_{j, i}$ is the cumulative fractional completion of development for the stage.

Each vector pair is evaluated once on each time step. In the simplest case there is no variation among individuals in stage duration. For each element pair, when the fraction $\mathbf{D}_{j, i} \geq 1.0$, then the abundance estimate $\mathbf{A}_{j, l}$ is transferred to the first element of $\mathbf{A}_{j+1,1}$, that is, $\mathbf{A}_{j+1,1}$ $:=\mathbf{A}_{j+1,1}+\mathrm{S}_{j} \cdot \mathbf{A}_{j, i}$, where $\mathrm{S}_{j}$ is the survivorship assigned to stage $j$. A variable number of elements of $\mathbf{A}_{j}$ may have $\mathbf{D}_{j, i} \geq 1$. on any given time step, so that $\mathbf{A}_{j+1,1}$ can fluctuate. In the case of C5's, elements of $\mathbf{A}_{12}$ with $\mathbf{D}_{12, i} \geq 1$. are added to the new resting stock resulting from $G_{1}$. When the value of $\mathbf{D}_{j, i}$ is less than 1.0, then both the abundance and development fractions are transferred to the next age-within-stage element: $\mathbf{A}_{j, i+1}$ $:=\mathrm{S}_{j} \cdot \mathbf{A}_{j, i}$ and $\mathbf{D}_{j, i+1}:=\mathbf{D}_{j, i}$. Incrementing of $\mathbf{D}_{j, i}$ and transferring the new value to $\mathbf{D}_{j, i+1}$ are separated in the program sequence. At each time step the first elements of all development vectors are set to zero, $\mathbf{D}_{j, 1}:=0$. for $j=1$ and 12 . In a slightly more complex case, a frequency distribution for molting as a function of $\mathbf{D}_{i, j}$ is applied at each time step. This mimics the effect of variable stage duration.

Stage-specific survivorship rates, $\mathrm{S}_{j}$, were arbitrarily selected for the standard run so as (1) to allow overall

Table 1. Symbols used in presenting the Calanus finmarchicus population model

\begin{tabular}{|c|c|}
\hline Symbol & Definition \\
\hline j & $\begin{array}{l}\text { Stage number: } 1=\text { egg, } 2=\mathrm{N} 1,8=\mathrm{C} 1 \\
13=\mathrm{C} 5 \text {-diapause }\end{array}$ \\
\hline$i$ & Time step number \\
\hline $\mathbf{A}_{j, t}$ & Abundance of stage $j$ in its $i^{\text {th }}$ age class \\
\hline $\mathbf{a}_{j}$ & Belehrádek constant for duration of stage $j$ \\
\hline $\mathrm{B}$ & Stock biomass (dry weight mass $\mathrm{m}^{-2}$ ) \\
\hline $\mathrm{C} 1-\mathrm{C} 6$ & First to sixth copepodite stages \\
\hline $\mathbf{D}_{j, I}$ & $\begin{array}{l}\text { Fraction of stage development completed by } \\
\text { individuals of } i^{\text {th }} \text { age within stage } j\end{array}$ \\
\hline JD & $\begin{array}{l}\text { 'Julian Day', consecutive number of day of the } \\
\text { year; JD } 1=1 \text { January }\end{array}$ \\
\hline $\mathrm{G}_{0}$ & $\begin{array}{l}\text { Number of generation completing diapause } \\
\text { early in model year }\end{array}$ \\
\hline $\mathrm{G}_{1}$ & Offspring of $\mathrm{G}_{0}$ females \\
\hline$g_{j}$ & Growth rate of stage $j$ \\
\hline$M R_{j}$ & Molting rate of stage $j$ (including all ages within $\mathrm{j}$ ) \\
\hline N1-N6 & First to sixth naupliar stages \\
\hline $\mathrm{S}_{\text {, }}$ & Finite daily survivorship of stage $j$ \\
\hline $\mathrm{W}_{j, i}$ & Weight of stage $\mathrm{j}$ individuals at $\mathrm{D}_{,, i}$ \\
\hline $\mathrm{W}_{\mathrm{lo}, \mathrm{J}}$ & Newly molted weight of stage $j$ individuals \\
\hline
\end{tabular}




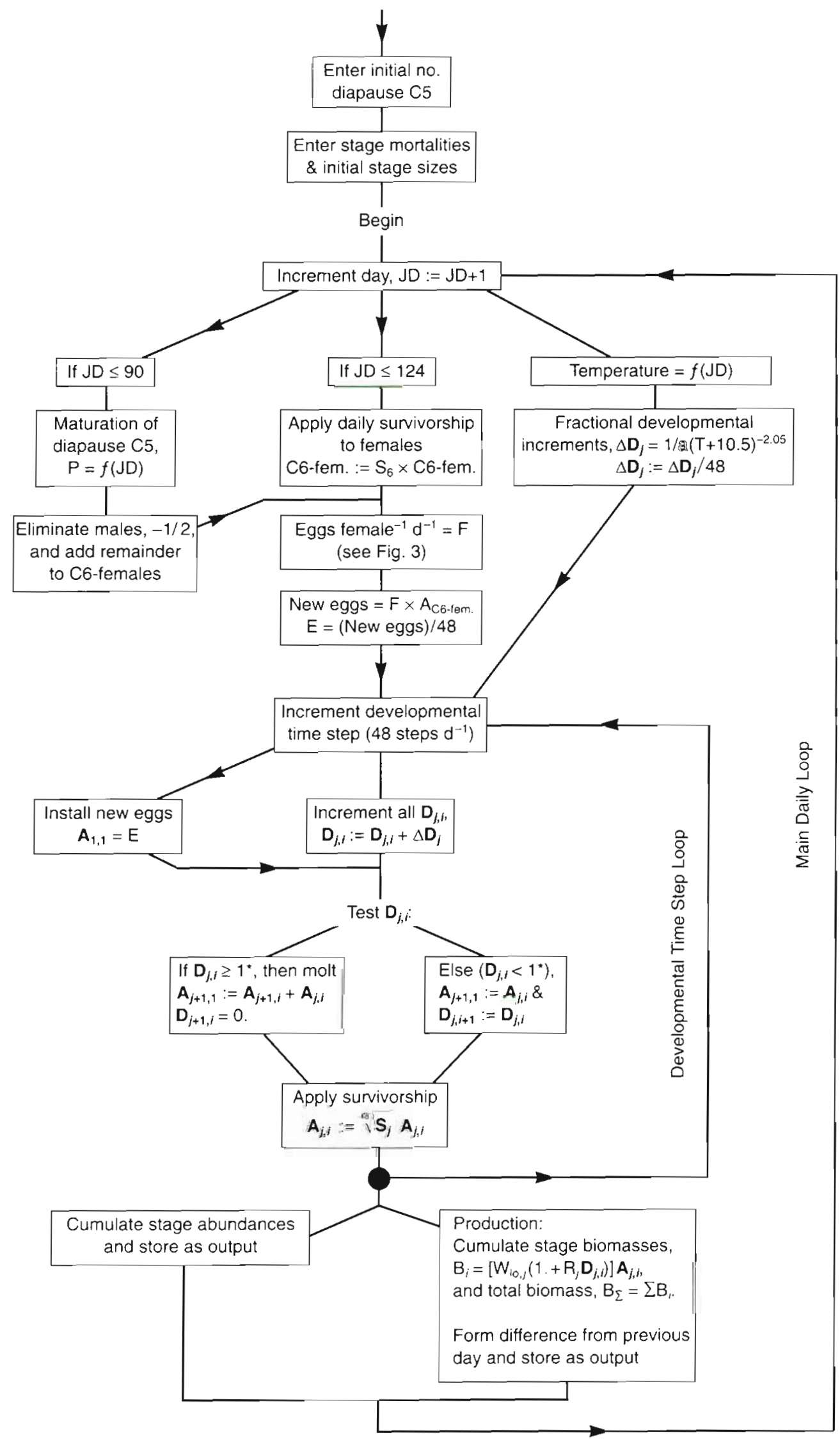

Fig. 1. Process flow diagram for age-within-stage model of population development in Calanus finmarchicus. Alternative criteria for variable development timing are applied at the single " (development time step loop). Regression coefficients for growth rates of stages, $R_{j}$ (applied at bottom right), are given in Table 2 
Table 2. Parameters of the MALANGEN version of the Calanus finmarchicus population model. JD: Julian Day

Temperature: $T(J D)=6.25+2.75 \sin [2 \pi(199+\mathrm{JD}) / 365]$

Maturation probability for diapause C5: cumulative normal with $\mu$ at

$$
\mathrm{JD}=45, \sigma=20 \mathrm{~d}
$$

Female survivorship after maturation (finite daily rate): $0.985 \mathrm{~d}^{-1}$

Egg production function: Eggs female ${ }^{-1}=27 . \times[1 .-(107-J \mathrm{D}) / 33$.$] ,$ for $\mathrm{JD}=74$ to 107

Eggs female ${ }^{-1}=27 . \times[1 .-(\mathrm{JD}-107) / 17$.$] ,$

for $J D=108$ to 123 )

Belehrádek function coefficients for stage durations and finite daily survivorship rates for naupliar and copepodite stages:

\begin{tabular}{|c|c|c|c|c|}
\hline Stage & $\begin{array}{l}\text { (coefficient } \\
\text { from Corkett } \\
\text { et al. 1986) }\end{array}$ & $\begin{array}{l}\text { (coefficient } \\
\text { used in } \\
\text { MALANGEN) }\end{array}$ & $\begin{array}{l}\text { Finite daily } \\
\text { survivorship }\end{array}$ & $\begin{array}{l}\text { Lowest stage } \\
\text { weight, } W_{\text {lo }} \\
\left(\mu \mathrm{g} \text { dry wt ind }{ }^{-1}\right)\end{array}$ \\
\hline Egg & 691. & 691. & 0.850 & 0.700 \\
\hline $\mathrm{N} 1$ & 1069. & 1069. & 0.920 & 0.700 \\
\hline N2 & . & . & & 0.700 \\
\hline N3 & . & . & . & 0.700 \\
\hline N4 & & . & & 0.800 \\
\hline N5 & . & & & 0.900 \\
\hline N6 & 1069. & 1069. & 0.920 & 1.000 \\
\hline $\mathrm{C} 1$ & 1595. & 1595. & 0.950 & 2.317 \\
\hline $\mathrm{C} 2$ & 1802. & 1700. & 0.960 & 4.810 \\
\hline $\mathrm{C} 3$ & 1785. & 1810. & 0.970 & 9.990 \\
\hline $\mathrm{C} 4$ & 1925. & 1925. & 0.980 & 20.75 \\
\hline $\mathrm{C} 5$ & 3951. & 5584 & 0.990 & 43.12 \\
\hline C5-dia & use & & 1.000 & 89.64 (fixed) \\
\hline \multicolumn{5}{|c|}{ Biomass as a function of stage and age-within-stage: } \\
\hline \multicolumn{5}{|c|}{$\begin{array}{l}\mathrm{N} 1 \text { and } \mathrm{N} 2: \text { Stock biomass }=(\text { Numbers in age step }) \mathrm{W}_{10} \\
\mathrm{~N} 3 \text { to } \mathrm{N} 6: \text { Stock biomass }=(\text { Numbers in age step })\left(\mathrm{W}_{10}+0.1 \mathbf{D}_{, .,}\right) \\
\mathrm{C} 1 \text { to } \mathrm{C} 4: \text { Stock biomass }=(\text { Numbers in age step })\left[\mathrm{W}_{10}\left(1+1.077 \mathbf{D}_{j, i}\right)\right] \\
\mathrm{C} 5 \text { to diapause: Stock biomass }=(\text { Numbers in age step })\left[\mathrm{W}_{10}\left(1 .+2.33 \mathbf{D}_{j, .1}\right)\right]\end{array}$} \\
\hline
\end{tabular}

survival of approximately 4 individuals entering diapause as C5 for each hundred eggs spawned, (2) to concentrate mortality in the naupliar phase, and (3) to give 'reasonable' relative abundances of the copepodite stages. Tests of various other schedules of $S_{\text {, }}$ are reported.

The mechanics of the model in these respects are like those described by Carlotti \& P. Nival (1992, particularly their Fig. 2). However, we made important changes. They have an $0.25 \mathrm{~d}$ step for age-withinstage, but an hourly time step for the model run. In our model the vectors have an age step for each time step. Our model was based on finite differences from the outset, not as an implicit solution to a set of differential equations as in the case of the Carlotti models. Another difference is that those models are driven by submodels that produce data about food availability, which (as discussed above) is not a concern in our present study. Models of the type used here differ from those employed by Slagstad (1981). Slagstad \& Tande (1990), and Tande \& Slagstad (1992), where development was a continuous function of temperature and food availability, and stages were arbitrarily assigned to successive sections of the development scale (a model of this general kind is used by Miller in press in a study of $\mathrm{NeO}$ calanus plumchrus). The effects of this difference have not yet been very fully explored. The Slagstad models are also driven by submodels for food availability.

Our model represents the calendar year from 1 January onwards, shown in our graphs on a 'Julian Days' (JD) axis. It is initiated by specifying the number of resting $\mathrm{C} 5 \mathrm{~m}^{-2}$ in the region to be modelled, half of which are taken to be male. Resting C5 mature at a fractional daily rate which increases in sigmoid fashion (Fig. 2) from 0 to 1. Once matured, females are subject to a mortality rate which interacts with the maturation schedule to produce the time course of female abundance. On each model date the per capita egg output rate is set by a function (Fig. 3) derived from the data collected from the Calanus finmarchicus population in Malangen fjord in 1989 (Diel \& Tande 1992). Several other spawning rate functions of different forms were tried to show the influence of this initiating function on the progression of stages in the model. Each day's total egg production (no. of females $\times$ per capita daily fecundity) is allotted into the vector of egg abundance according to the number of time steps per day. Thus, if the time step is $0.5 \mathrm{~h}$, then $1 / 48$ of the total eggs for the day are installed at each step in $\mathbf{A}_{1,1}$, the first age-within-stage element of the egg vector.

The model provides a rough estimate of biomass production attributable to the growth of $\mathrm{G}_{1}$. Each model day the biomass is calculated by multiplying the stage abundances $\left(\mathbf{A}_{j}\right)$ by an individual weight $\left(\mathrm{W}_{i}, \mathrm{mg}\right.$ dry wt) appropriate to the developmental progress within the stage $\left(\mathbf{D}_{j, i}\right)$. These products are summed over the stages $\left(\mathrm{B}=\Sigma, \Sigma, \mathrm{W}_{i} \cdot \mathbf{A}_{j, i}\right)$, and productivity is the increment over the previous day's biomass. Weight increments within stages are added to estimates of the initial weights of the stages, $\mathrm{W}_{j}$, taken from Peterson's (1986) data for Calanus marshallae. This Pacific species has the same range of terminal weight as 


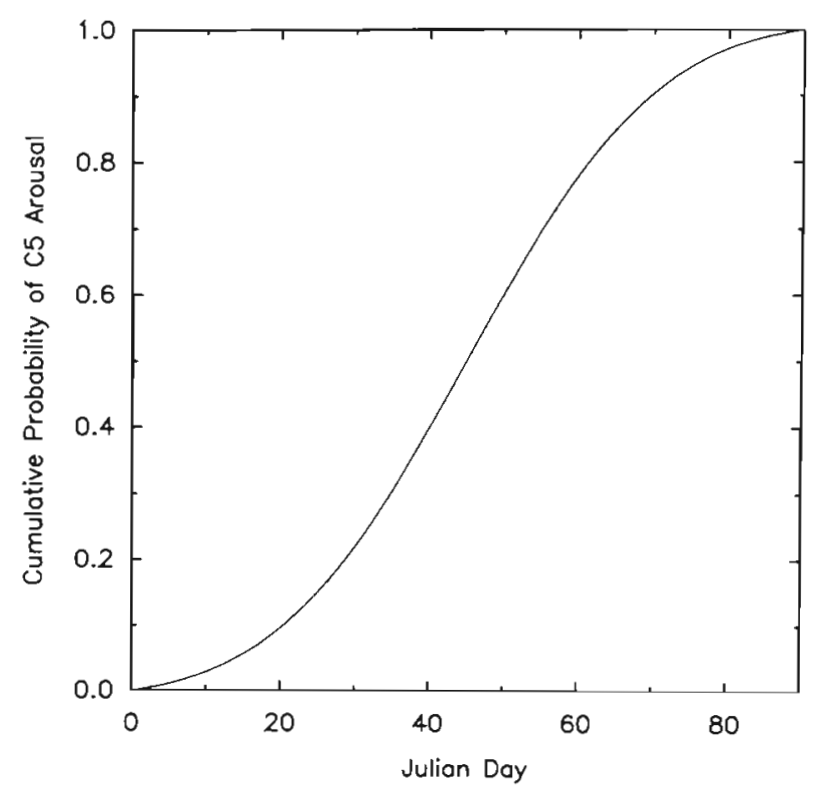

Fig. 2. Probability of individual $\mathrm{C} 5$ breaking diapause and maturing, as a function of date

C. finmarchicus, and Peterson's data provide careful weighings for all stages. Weight increments were calculated from the slopes of Peterson's regressions of weight vs stage (Table 2). Carlotti et al. (1993) have provided an analysis of the effect of temperature on body weight as a function of habitat temperature in C. finmarchicus. Their function could be incorporated

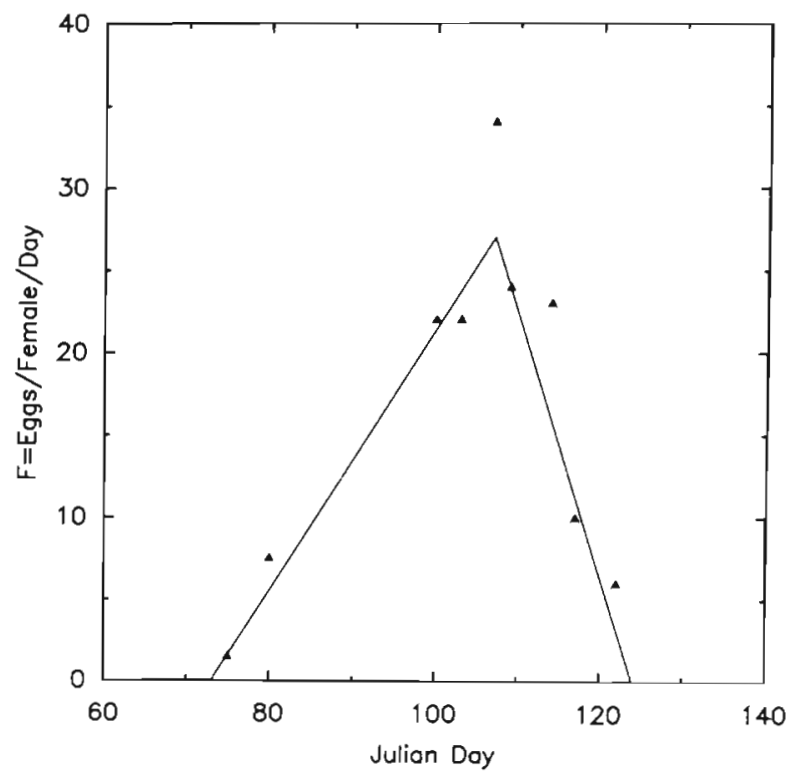

Fig. 3. Per capita egg production rate in Malangen Fjord from data of Diel \& Tande (1992). Plotted points are the actual estimates; fitted lines are the spawning function used in MaLA.NGEN. Overall rate varies with changes in both eggs per spawning and spawning frequency in the model to give a more precise estimate of biomass production, but for now that has not been done.

Model temperature is specified by a simple sine function. This was varied with the location to be simulated, and the approximation is shown for each case presented. Results are presented showing the impact of different temperature patterns.

The realization of the model is a FORTRAN-77 program which was run on a Sun SPARC-1+ workstation. Copies of the program for our standard run or for special 'experiments' are available from the authors on request.

\section{SPECIFIC SIMULATIONS, RESULTS AND EXPLANATIONS}

Our results divide into 2 groups: studies of the characteristics of the model itself, and simulations of techniques for evaluation of developmental progress (stage duration) in the field.

\section{The Malangen case, a standard run}

Parameter values employed in our standard version of the model (hereafter called MALANGEN) are given in Table 2. All of these values are intended to represent the population processes of Calanus finmarchicus in Malangen Fjord, northern Norway. Seasonal temperature variation in the model (Fig. 4) was fit to data from $20 \mathrm{~m}$ in Malangen Fjord from February to December 1990. Interaction of C5 maturation (Fig. 2), female mortality $\left(0.015 \mathrm{~d}^{-1}\right)$, and the spawning function (Fig. 3) produced a total of $1.03 \times 10^{6}$ eggs from an original stock of ca 5000 females, an average just over 200 eggs apiece, well within the production capacity of the species, but reasonable since mortality removes many before spawning is complete. $\mathrm{G}_{0}$ females were arbitrarily removed after the spawning function dropped to zero by increasing their mortality to $0.15 \mathrm{~d}^{-1}$.

Survivorship values were selected to give about 4 $\mathrm{G}_{1}-\mathrm{C} 5$ entering diapause at the end of the growing season for each $\mathrm{G}_{0}$ - $\mathrm{C} 5$ maturing after 1 January. Overall survivorship of $4 \%$ allows for an $0.0067 \mathrm{~d}^{-1}$ mortality (6.68 deaths per thousand individuals per day) over the $210 \mathrm{~d}$ diapause phase, bringing the $\mathrm{G}_{1}$ stock back to the starting place of $G_{0}$, as it becomes the new $\mathrm{G}_{0}$ the following winter. We have no idea whether this is a reasonable mortality rate for the resting stock or not, but new field research could give an approximate answer. The survivorship value for nauplii produces a peak naupliar abundance of $13 \mathrm{l}^{-1}$ (integrated over $25 \mathrm{~m}$ ) (Fig. 5), in general agreement with observations 


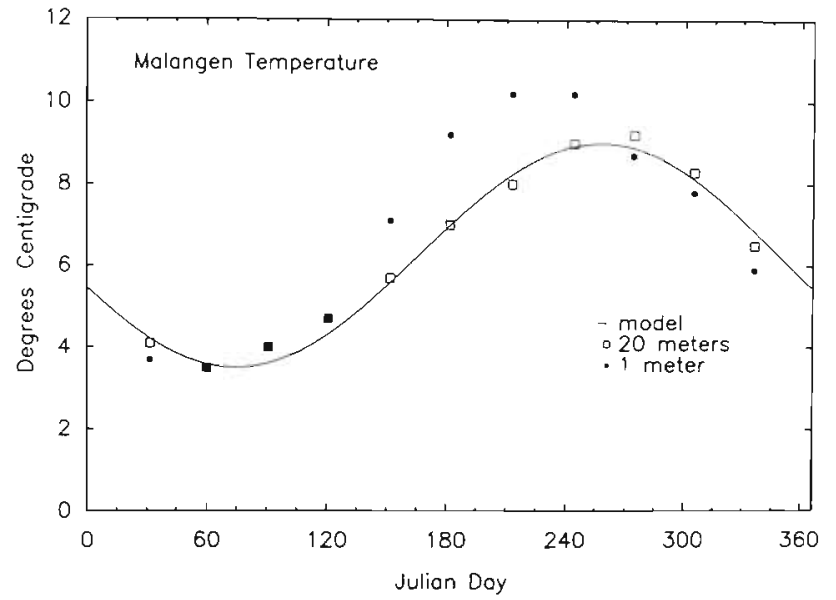

Fig. 4. Solid curve: temperature variation in Malangen Fjord from a fitted sine function. Open boxes show $20 \mathrm{~m}$ temperature in Malangen Fjord, 1990. Filled boxes show that surface layer was slightly warmer in spring and summer. Calanus finmarchicus avoids this layer because of reduced salinity

from Lofoten, Norway. In an elaborate study by Ellertsen et al. (1989) of the spawning behavior and larval survival of cod, the abundance of Calanus nauplii peaked in April at 15 to 20 nauplii $\mathrm{l}^{-1}$ in $4 \mathrm{yr}$ between 1980 and 1985. MALANGEN first produced copepodites (Fig. 5) on JD 105 (April 15), and the last C5 entered diapause on JD 185 (July 4). The timing of the stage progression is realistic for north Norwegian fjords, and copepodite abundances are within the range observed in fjords and shelf areas during the annual recruitment (Tande \& Slagstad 1992). Survivorship and mortality curves (Fig. 6) for the $\mathrm{G}_{1}$ stock show concentration of mortality in the naupliar stages. This

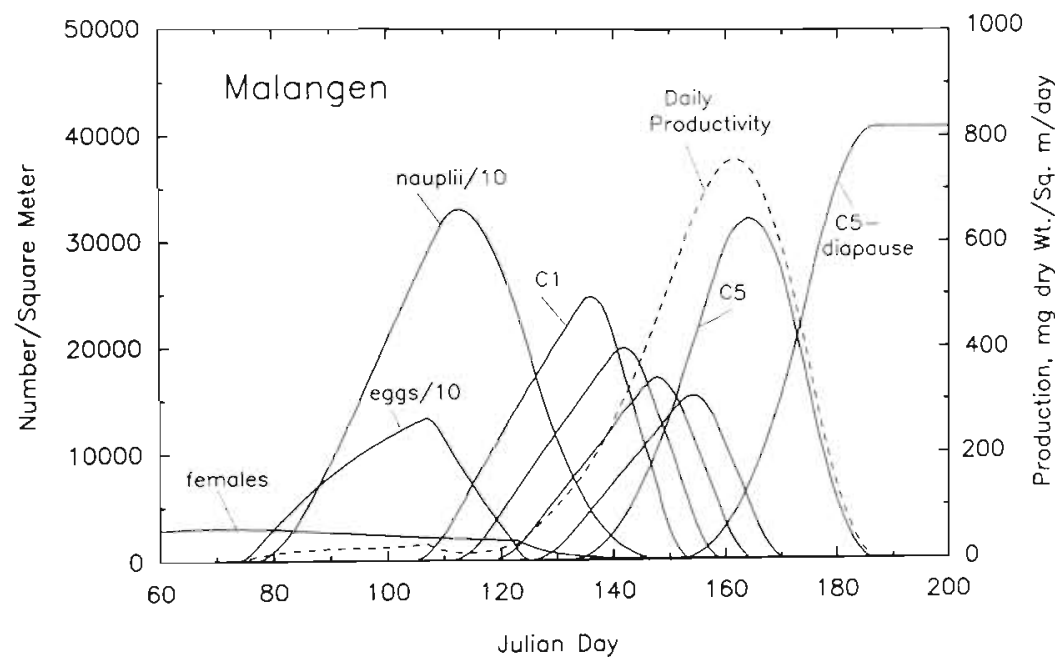

Fig. 5. Output of the standard or MALANGEN version of the model. Abundances of successive stages shown by solid lines. Daily production increments shown by dashed line. Total production was $12.3 \mathrm{~g}$ dry wt $\mathrm{m}^{-2}$. Initial number of $\mathrm{G}_{0} \mathrm{C} 5$ was $10000 \mathrm{~m}^{-2}$ mostly occurs simply because the naupliar phase comes first and lasts nearly half the life cycle. There are more of them, so they suffer the most mortality regardless of small differences in rates between stages

\section{Effect of time step size}

MaLANGEN has $48(1 / 2 h)$ time steps per day. The choice of time-age steps has strong effects on the model. A run like MALANGEN, but with just one time and age step per day (Fig. 7), has substantially lower survival (2.9 $\mathrm{G}_{1}$-C5 entering diapause per hundred eggs spawned) and production (annual total $=8.83 \mathrm{~g}$ dry wt) than runs with higher resolution. Both survival and production are nearly asymptotic with half-hour time steps, being very slightly less than from a run with 200 time-age steps $\mathrm{d}^{-1}$. The reason for this improved survivorship is that development is significantly faster. All 'individuals' (all $\mathbf{D}_{f, i}$ ) that reach 1.0 can graduate nearly immediately, rather than having to wait for the end of the day. For example, if the required stage duration is $5.1 \mathrm{~d}$, the 'saving' of time in a high resolution model will be $0.9 \mathrm{~d}$. Moreover, since mortality is modelled as decreasing with advancing stage, overall survivorship is also enhanced by reduction of time at younger, more susceptible stages. It is possible that a model might be desired in which molting was restricted to some part of the day, say night (Miller et al. 1984). In that case it is better to explicitly atd this condition on molting to the model, rather than to let long time steps provide the effect artificially. In addition to enhanced survivorship, the output of high resolution models is smooth at the resolution of the plotting, which is not true at one step per day (Fig. 7). The drawback of high resolution is running time. At 1 time-age step $\mathrm{d}^{-1}$, MALANGEN runs in under $2 \mathrm{~s}$ (Sun

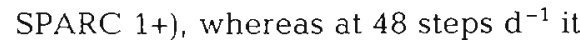
requires over $5 \mathrm{~min}$.

Incorporation of refined time steps must be done with care about the form of the development and survivorship functions. The daily increments to $\mathbf{D}_{j, i}$ must be divided by 48 for application each half hour. As we have formulated survivorship, it is entered as a finite daily rate, which with one time step per day is multiplied by the abundance to give the new abundance. Thus, $\mathbf{A}_{j, i+1}(\mathrm{JD}+1):=\mathrm{S}_{j} \cdot \mathbf{A}_{j, f}(\mathrm{JD})$. If survivorships are to be applied twice daily by this multiplicative rule, giving the 


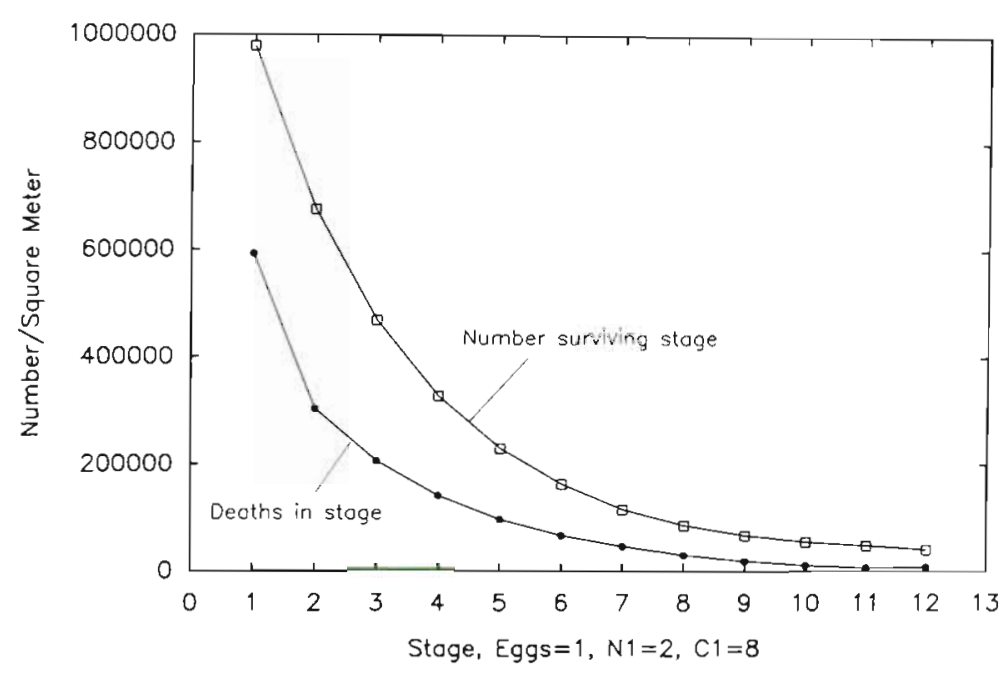

Fig. 6. Stage-by-stage survivorship and mortality curves for the MALANGEN model

same result, the replacement becomes $\mathbf{A}_{j, i+1}(J D+1 / 2):=$ $\left(\mathrm{S}_{j}\right)^{1 / 2} \cdot \mathbf{A}_{j, f}(\mathrm{JD})$. For half-hour time steps, the survivorship multiplier is the 48 th root of $\mathrm{S}_{j}$.

All versions of the model, including MALANGEN, have a good deal of hidden numerical 'chatter'. This is brought out by plotting the age-within-stage distribution of a given stage for several dates during the passage of the stock through that stage (Fig. 8). These are plots of successive $\mathbf{A}_{10, i}$ (C) for all occupied age-within-stage steps. The strong, narrow spikes develop because several $\mathbf{A}_{j, i}$ can transfer to $\mathbf{A}_{j+1,1}$ on some time steps. The numbers of elements

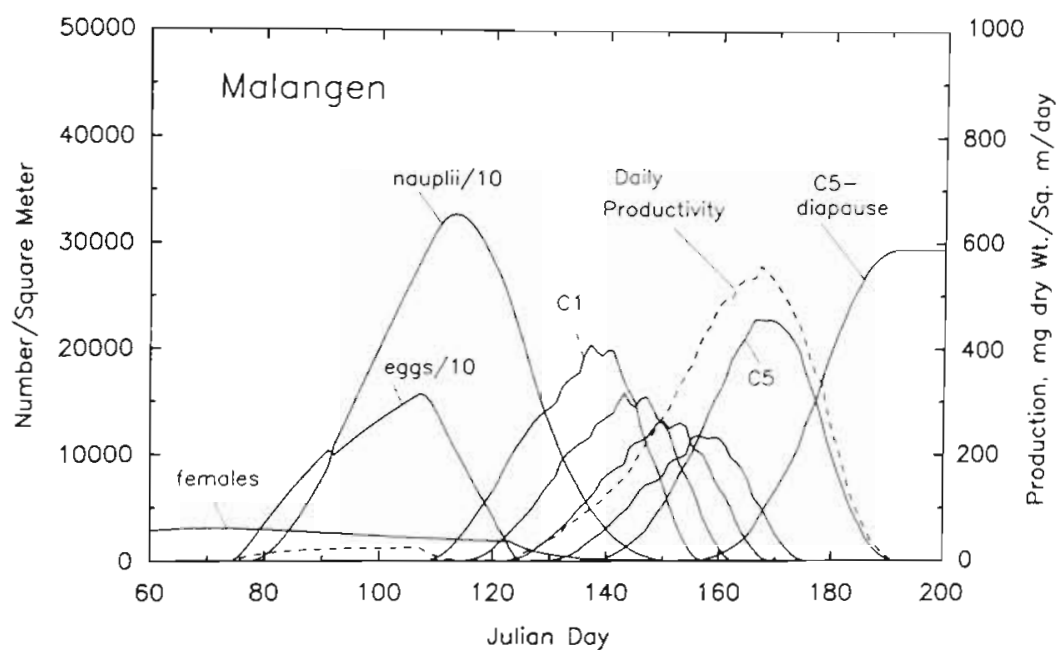

Fig. 7. Output of model with same parameters as MaLANGEN, but only one time step per day. Stage abundance sequences are somewhat erratic. Both survivorship and production (total $=8.83 \mathrm{~g}$ dry $w t \mathrm{~m}^{-2}$ ) are reduced. The 'tooth' in egg abundance at JD $=90$ is caused by completion on that day of maturation of $\mathrm{G}_{0}$-C5's. For $2 \mathrm{~d}$ female mortality overrides the increasing per capita fecundity (Fig. 3)
$\mathbf{A}_{j, i}$ making this transfer and their total may vary widely among time steps. So far as we can determine, this numerical chatter does not impede the reliability of the model as a representation (Fig. 5) of development timing in Calanus finmarchicus.

\section{Effects of variable stage duration}

Five simulations were run to examine the effects of variation of stage duration between individuals on timing of the stage progression and on other aspects of model output. In VAR-1 through VAR-5 the probability of molting was allowed to increase as a function of $\mathbf{D}_{j, i}$ in the patterns shown in Fig. 9. All patterns that allow some individuals to molt early (VAR-1, VAR-2, VAR-4) gave enhanced overall survival and productivity together with completion of later stages several days ahead of the MaLANGEN schedule (Table 3). Enhanced survival in those cases derived from earlier arrival of some individuals at later stages, reducing the duration of their exposure to the higher mortality rates for early stages. Patterns in which some individuals had their molting delayed to various degrees (VAR-3 and VAR-5) were only slightly affected, with small reductions in survivorship and production. The impact of early advance was much stronger than roughly equivalent delay (VAR-1 and VAR-2) when both occurred together. The model suggests strong selective advantage will accrue to individuals that reduce stage duration. The effect is such that average stage durations we observe in Calanus finmarchicus today must already have been minimized by recurring selection of this kind in the past. There must also be countervailing selective costs preventing further shortening. A different sort of model has been used by Myers \& Runge $(1983,1986)$ to explore the selective tradeoffs among growth rate, stage duration, and survivorship.

\section{Effects of the temperature increase schedule}

Timing of the seasonal temperature cycle has a strong effect on the model and presumably on the timing of real 

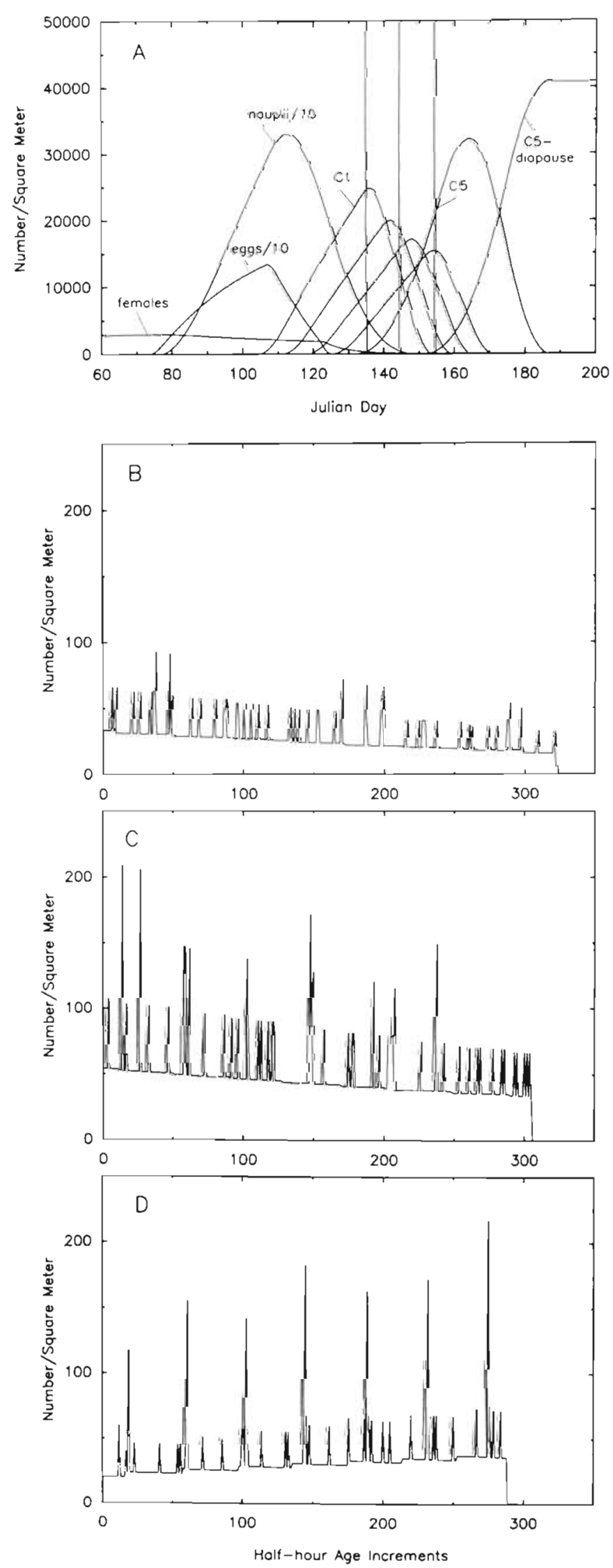

Calanus finmarchicus cohorts. As a simple example, MALANGEN was modified only by changing the temperature function to fit data from Georges Bank (Fig. $10 \mathrm{~A}$, where the seasonal low is comparable to that in fjords in northern Norway, but the spring warming is more rapid and the summer maximum higher. Overall survivorship (Fig. 10B) increased to 64000 ind. $\mathrm{m}^{-2}$ and production increased by over $50 \%$. Copepodites appeared at nearly the same time, but $\mathrm{C} 4$ was completed $12 \mathrm{~d}$ earlier and C5 $16 \mathrm{~d}$ earlier. The greater rapidity of development (enforced, of course, by the Belehrádek function) accounts for the improved survivorship and production through reduction of exposure to mortality at fixed rates. Reality of a Georges Bank version eventually can be enhanced by including a site-appropriate spawning function, although the temperature difference from Malangen isn't great during the spawning season. Mortality rates may increase at higher temperatures through a general speeding up of all ecological processes including predation

Sensitivity analyses have been carried out to examine the consequences for a field population of the effects of a temperature regime studied experimentally by Pedersen \& Tande (1992). In their experiments, eggs and then nauplii were held at $2^{\circ} \mathrm{C}$ until completion of the late naupliar phase, then programmable temperature control baths held one group at $2^{\circ} \mathrm{C}$, warmed another at $0.1^{\circ} \mathrm{C} \mathrm{d} \mathrm{d}^{-1}$, and warmed a third at $0.2^{\circ} \mathrm{C} \mathrm{d}^{-1}$. Mortality observed in the laboratory was progressively less severe for those groups given faster warming. In order to look at this aspect in more detail, we performed 2 series of model tests (Table 4 ). In the first series (PT-1 to PT-5) MALANGEN was changed only with respect to temperature. It was held constant until $\mathrm{JD}=120$, then increased according to the schedules in Table 4 (Series 1). Both integrated survivorship and production increased monotonically with the rate of temperature increase because of reduced stage duration and, thus, shorter exposure to fixed mortality rates. However, all simulations had less productivity than MALANGEN because of lower temperatures early in the season and later onset of warming. Not only the rate of increase (actually higher in PT-5 than in MALANGEN), but also the time when warming starts in spring affects the final outcome. Delay in warming slowed arrival of the stock at early copepodite stages (10 d delay of the C1 peak in PT-4 compared to

Fig. 8. Age-within-stage distributions for C3 from MALANGEN. Age distributions on 3 dates indicated by vertical lines in $(A)$ are shown by half hour intervals in (B) for $J D=135$, in (C) for $\mathrm{JD}=145$ and in (D) for JD $=155$ 


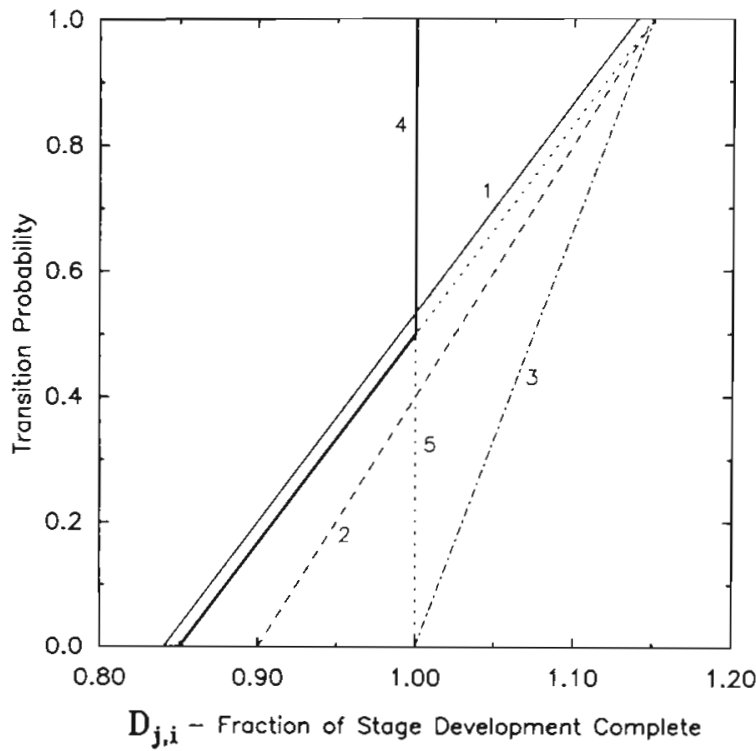

Fig. 9. Patterns of variation in probability of molting, $P_{m}$ as a function of $\mathbf{D}_{j, k}$. Patterns were (1) linear increase from $\mathbf{D}_{j, 1}=0.85$ to 1.15 ; (2) linear increase from $\mathbf{D}_{j, k}=0.90$ to 1.15 ; (3) linear increase from $\mathbf{D}_{j, i}=1.0$ to $1.15_{i}(4)$ linear increase at same rate as pattern (1) from $D_{f, I}=0.85$ to 1.0 , then $P_{m}=1.0_{i}(5) P_{m}=0$. until $\mathbf{D}_{f, i}=1.0$, then linear increase at rate of pattern (1)

MALANGEN) with a tendency to more overlap in successive abundance curves later in the spring.

In the second series (PT-6 to PT-9), we evaluated the effect of variable survivorship regimes derived from the instantaneous mortality constants determined in laboratory rearings (Pedersen \& Tande 1992). These alternate survivorship schedules were initiated on model day JD $=120$, the approximate equivalent of the experimental transfer of experimental stocks to different increase regimes. In the experiments, the largest proportions of the stock when different warming schedules were applied were in N4 and N5, roughly the same as for MALANGEN on JD $=120$. Although the naupliar development period found by Pedersen \& Tande was longer than expected for $2{ }^{\circ} \mathrm{C}$ according to Corkett et al. (1986), the discrepancy (for

Table 3. Output of MALANGEN modified to use variable molting functions as shown in Fig. 9

\begin{tabular}{|cccc|}
\hline $\begin{array}{c}\text { Molting } \\
\text { probability } \\
\text { pattern }\end{array}$ & $\begin{array}{c}\text { Overall survivorship } \\
\text { to C5-diapause } \\
\text { (thousands) }\end{array}$ & $\begin{array}{c}\text { Integrated } \\
\text { production } \\
\text { (dry tissue weight, g) }\end{array}$ & $\begin{array}{c}\text { JD at peak of } \\
\text { C4 stock }\end{array}$ \\
\hline MALANGEN & 41 & 12.3 & 154 \\
VAR-1 & 58 & 17.5 & 149 \\
VAR-2 & 50 & 15.0 & 151 \\
VAR-3 & 37 & 11.2 & 157 \\
VAR-4 & 58 & 17.5 & 149 \\
VAR-5 & 40.5 & 12.1 & 154 \\
\hline
\end{tabular}

which reasons were given by Pedersen \& Tande) does not affect the conclusions from our model. We adapted the survivorship schedules from Pedersen \& Tande (1992, their Fig. 3) as shown in Table 4 (Series 2) and Fig. 11. After JD 120 in PT-6 to PT-9 there was no differential in survivorship between stages. Development was driven by the MALANGEN warming sequence; the mortality variations among PT- 6 to PT-9 were not compounded by the slowing of development resulting from slower warming. The simulations indicated that the non-predatory mortality observed in the absence, or near absence, of warming had severe impact on final cohort survival, and thus on productivity. In PT-6 no C5 reached diapause, and in PT-7 it was only a very few. High daily survivorship (PT-9), as obtained with the fastest experimental warming, produces unrealistically high survivorship and production. It shows, however, the favorable impact of warming on the stock, apart from possible effects on predation. The subtle step in survivorship from PT- 7 to PT- 8 shows that the model is very sensitive to variations in survivorship constants. The result underlines the contention (Pedersen \& Tande 1992) that substantial changes in productivity are likely to occur if a temperature-dependent mortality operates during the annual recruitment period in Calanus finmarchicus. It clearly appears that more data on field mortality are needed in order to further explore this subject and substantiate this mechanism.

\section{Stage duration derived from time series of stage proportion estimates}

Two approaches to determination of stage duration in the field have been simulated with the model. We call these the 'Heinle graph' and 'Kimmerer experiment' methods after their originators. Neither method was developed for precisely the problem to which we apply it. Heinle graphs were originally applied to determination of stage durations in laboratory experiments (Heinle 1966, Johnson 1981, Landry 1983, Peterson 1986, Peterson \& Painting 1990). They have also been applied by Miller $\&$ Nielsen (1988), and Miller (in press) to field populations of Neocalanus plumchrus sampled in the Gulf of Alaska, and by Durbin \& Durbin (unpubl.) to Calanus finmarchicus in Great South Channel (Gulf of Maine). They are constructed by collecting a time series of samples of the population and determining the proportions of the stages in each. Cumulative values of the proportions at each sampling time 


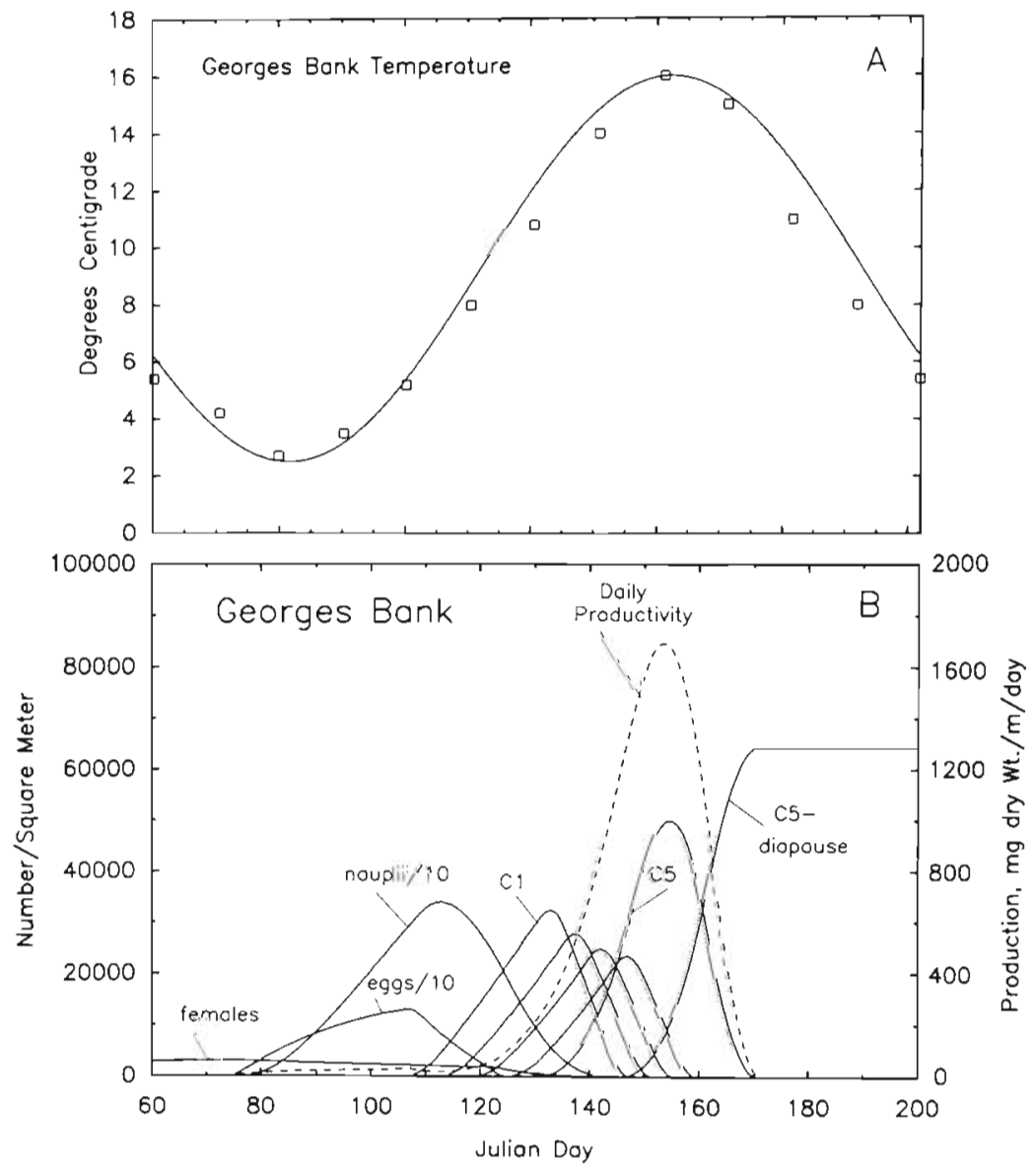

Fig. 10. (A) Temperature function for Georges Bank based on surface temperature data (open boxes) from Walsh et al. (1987). (B) Output of Georges Bank Calanus finmarchicus population model. Only the temperature function was changed from MALANCEN. Total production was $19.3 \mathrm{~g}$ dry wt $\mathrm{m}^{-2}$

Table 4. Alternate mortality schedules for model versions exploring the consequences of the Pedersen \& Tande (1992) rearing results

\begin{tabular}{|c|c|c|c|c|}
\hline Series & $\begin{array}{c}\text { Simulation } \\
\text { no. }\end{array}$ & $\begin{array}{c}\text { Temperature } \\
\left({ }^{\circ} \mathrm{C}\right)\end{array}$ & $\begin{array}{l}\text { Survivorship } \\
\text { rate schedule }\end{array}$ & $\begin{array}{c}\text { Productivity } \\
\text { (g dry wt } \mathrm{m}^{-2} \text { ) }\end{array}$ \\
\hline \multirow[t]{5}{*}{1} & PT-1 & 2.0 & As MALANGEN & 2.53 \\
\hline & PT-2 & $2+0.05 \mathrm{~d}^{-1}$ & As MALANGEN & 4.32 \\
\hline & PT-3 & $2+0.10 d^{-1}$ & As MaLangen & 6.04 \\
\hline & $\mathrm{PT}-4$ & $2+0.15 d^{-1}$ & As MALANGEN & 7.69 \\
\hline & PT -5 & $2+0.20 \alpha^{-1}$ & As MALANGEN & 9.15 \\
\hline \multirow[t]{4}{*}{2} & PT -6 & As MALANGEN & $\begin{array}{l}\text { As MALANGEN to } \\
\mathrm{JD}=120, \text { then as Fig. } 10\end{array}$ & 0.44 \\
\hline & PT-7 & As MALANGEN & $\begin{array}{c}\text { As MaLANGEN to } \\
\mathrm{JD}=120, \text { then as Fig. } 10\end{array}$ & 0.95 \\
\hline & PT -8 & As MALANGEN & $\begin{array}{c}\text { As Malangen to } \\
\mathrm{JD}=120, \text { then as Fig. } 10\end{array}$ & 14.11 \\
\hline & PT-9 & As MALANGEN & $\begin{array}{c}\text { As MaLANGEN to } \\
\mathrm{JD}=120, \text { then as Fig. } 10\end{array}$ & 40.8 \\
\hline
\end{tabular}

are then plotted as a vertical series, and points representing the sequence of cumulative proportions of each stage are joined by lines or represented by regressions against time. These 'transition curves' delineate the progress of the cohort's transition between successive stages.

The Heinle graph (Fig. 12A) for MALANGEN was calculated using data for only copepodite stages, leaving out nauplii. We believe this represents a realistic situation for field work, in which naupliar and copepodite stages must be estimated in different ways such that comparable numbers would be very difficult to obtain. A problem with this representation is that it does not include all of the cohort at the outset, only those individuals that have reached $\mathrm{C} 1$. Thus, the form of the early transition curves is greatly influenced by continuing recruitment from the naupliar stock. However, the form of the $\mathrm{C} 3 \rightarrow \mathrm{C} 4$ and $\mathrm{C} 4 \rightarrow \mathrm{C} 5$ transition curves is only very slightly influenced by continued recruitment to $\mathrm{C} 1$. In field work a check on the validity of this assumption could be obtained by examining the abundance of late nauplii. If it is negligible by the date at which $\mathrm{C} 3 \rightarrow \mathrm{C} 4$ crosses the median $(50 \%$ of total stock), then recruitment bias should be small. The time elapsed between crossings of the median line by the $\mathrm{C} 3 \rightarrow \mathrm{C} 4$ and $\mathrm{C} 4 \rightarrow \mathrm{C} 5$ transition curves is an only slightly biased estimate of the C4 stage duration. Precisely, the estimate for MALANGEN was $5.83 \mathrm{~d}$ (indicated by vertical lines in Fig. 12A), while the Belehrádek function expectation for the $5.66^{\circ} \mathrm{C}$ temperature at the midpoint on $\mathrm{JD}=$ 153.47 was $6.33 \mathrm{~d}$. The downward bias is caused by the differential in mortality among the stages (Hairston \& Twombly 1985, Miller in press). If mortality is progressively less at successive stages, then later stages will accumulate relative abundance faster than their development rate alone would predict, shortening the time elapsed between crossings of the median by successive transition curves. For Malangen the bias is $-0.50 \mathrm{~d}$, or $8 \%$. 


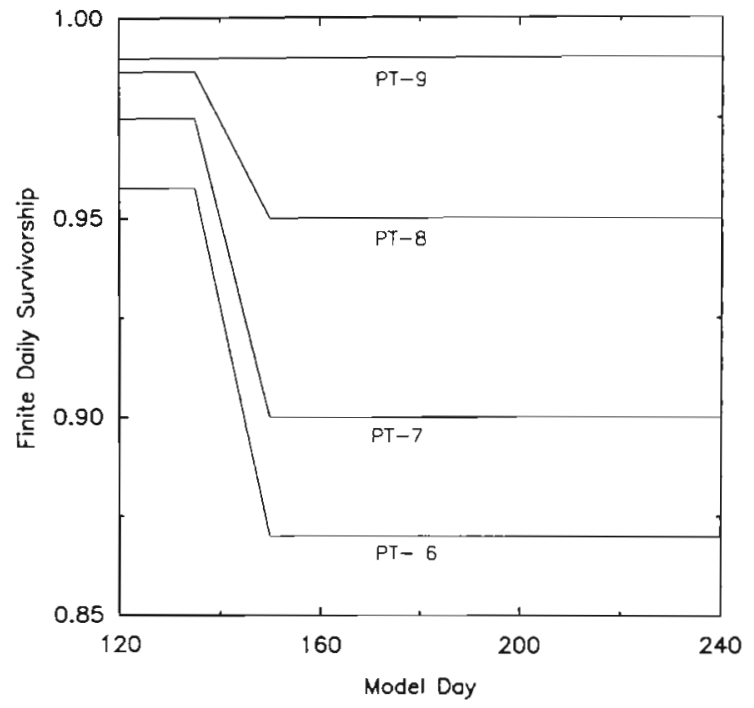

Fig. 11. Survivorship patterns applied after JD $=120$ in PT-6 to PT-9. These patterns represent the effects on survivorship observed for different warming schedules by Pedersen \& Tande (1992). PT-6 was abserved at constant $2^{\circ} \mathrm{C}$, PT-7 with warming at $0.05^{\circ} \mathrm{C} \mathrm{d}^{-1}, \mathrm{PT}-8$ with warming at $0.15^{\circ} \mathrm{C} \mathrm{d}^{-1}$, and PT-9 with warming at $0.20^{\circ} \mathrm{C} \mathrm{d}^{-1}$
Detailed simulations of varied mortality differentials show that this source of bias operates in our present models exactly as a different model by Miller (in press) suggested it should. That is, bias arises only from differentials in mortality between stages, not from mortality per se. A variant of MALANGEN called Constsurv was developed by making survivorship rates identical among stages, then changing its value until overall survivorship (Fig, 13A) was the same (output was $40851 \mathrm{C} 5 \mathrm{~m}^{-2}$ in diapause) as for Malangen. The Heinle graph estimate of $\mathrm{C} 4$ duration from CONSTSURV (Fig. 12B) was within $0.1 \%$ of the Belehrádek function expectation of $6.28 \mathrm{~d}$. The very slight discrepancy was due to nonlinearity in the time course of temperature change. Next, variants were developed with survivorship increasing $2 \% \mathrm{~d}^{-1}$ stage $^{-1}$ through the copepodite stages (INCSURV, Fig. 13B) and decreasing $2 \% \mathrm{~d}^{-1}$ stage $^{-1}$ (DECSURV, Fig. 13C). INCSURV required some increase of naupliar survivorship (Fig. 13B) to provide enough copepodites to support the high mortality in early copepodite stages. DECSURV required extremely high naupliar survival to provide enough copepodites to support the prolonged mortality at high rates in late
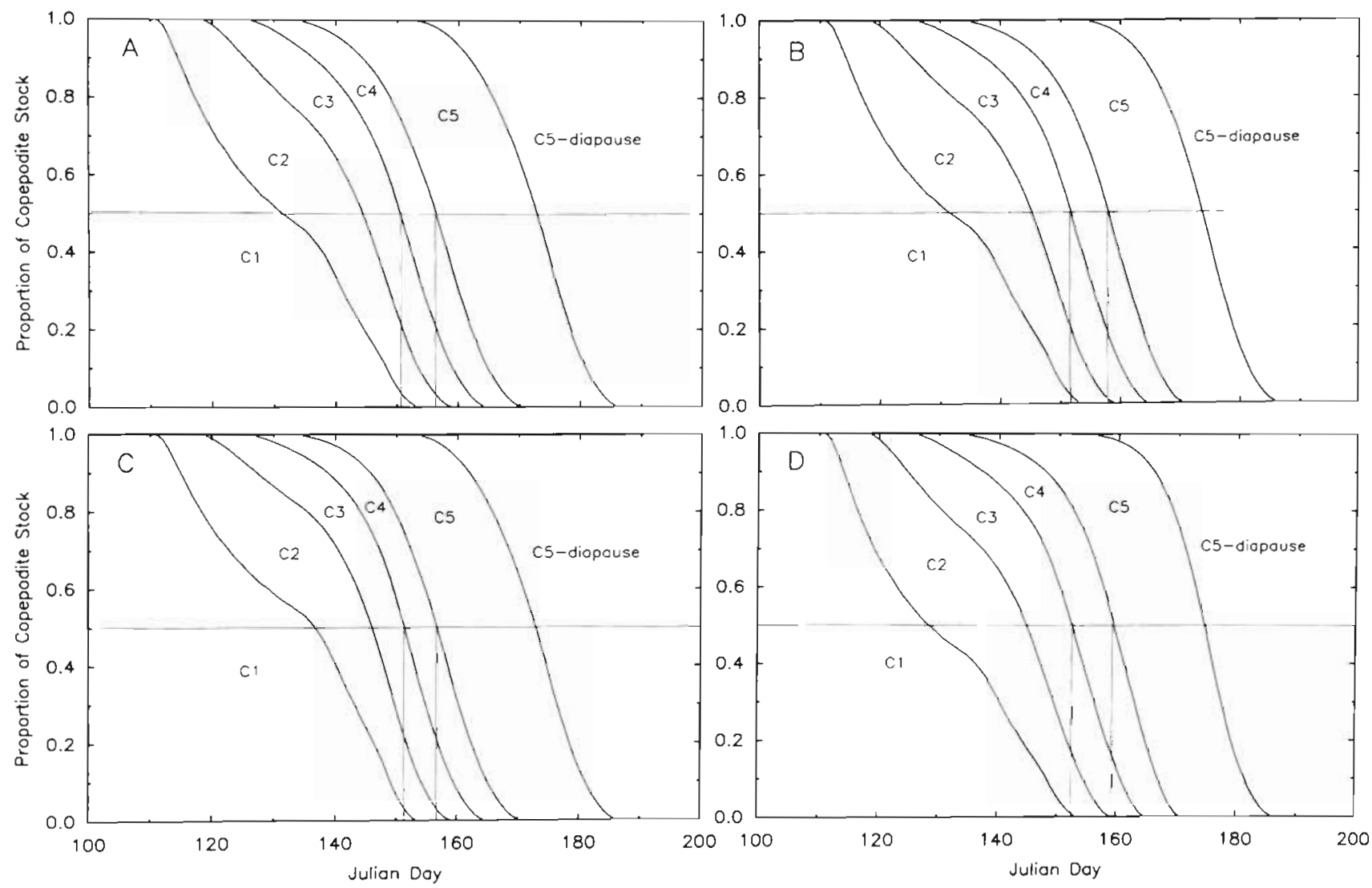

Fig. 12. (A) Stage proportion or Heinle graph for MALANGEN. Calculation of stage proportions is for copepodite stages only. Apparent duration of $\mathrm{C} 1$ and $\mathrm{C} 2$ is extended by continued recruitment from naupliar phase. Apparent duration of $\mathrm{C} 4$ is shown by vertical bars. (B) Heinle graph for Constsurv. (C) Heinle graph for INCSuRv (copepodite survivorship increased $2 \% \mathrm{~d}^{-1}$ stage $^{-1}$ (D) Heinle graph for DeCSURv (copepodite survivorship decreased $2 \% \mathrm{~d}^{-1}$ stage $^{-1}$ ) 

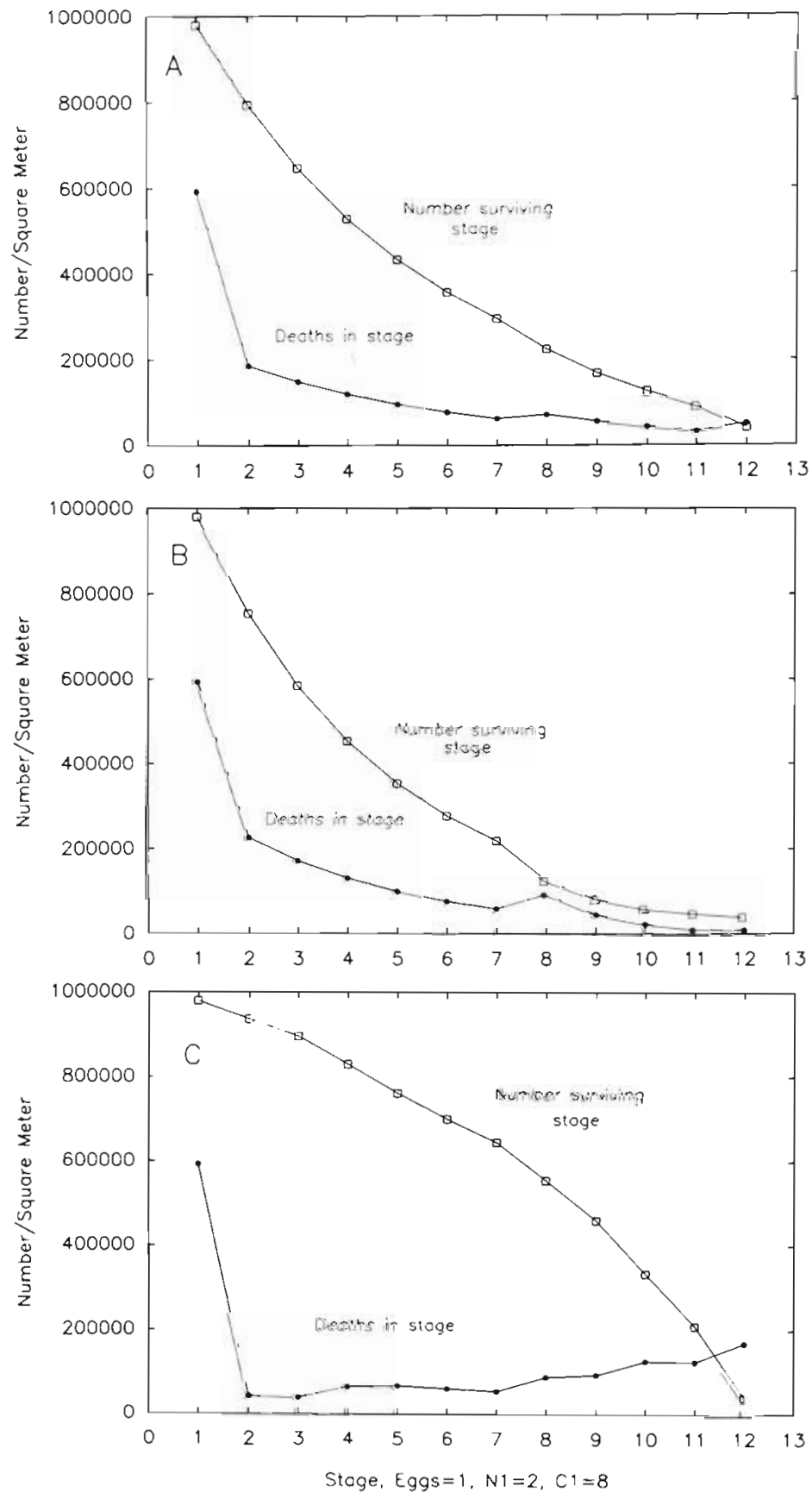

Fig. 13. Survivorship curves for (A) Constsurv, (B) Incsurv, and (C) Decsurv

copepodite stages. Both survivorship sets were tuned to produce the same final survivorship as MALANGEN. Heinle graphs (Fig. 12C, D) underestimated C4 duration by $23 \%$ in INCSURV and overestimated it by $13 \%$ in Decsurv. As pointed out above, there is no a priori reason to expect any particular pattern of survivorship differentials among stages. Thus, without separate information on survivorship, there is no certain way to determine the differential mortality bias of Heinle graph estimates.

We believe the examples are extreme; the bias generated in them by differential mortality among stages is important, but it does not overwhelm the value of Heinle graphs for obtaining approximate stage durations from Calanus populations in the field.

In addition to bias from differential mortality, stage duration estimates from Heinle graphs are affected by skewness in the spawning function. Two simulations, SKEwEARLY and SKEW-LATE, both based on MALANGEN, demonstrate the strength of this effect. Extreme skewing of egg production to early dates in SKEW-EARLY (Fig. 14A) reduced the Heinle measure of $\mathrm{C} 4$ duration from $6.63 \mathrm{~d}$ expected from the Belehrádek function to $5.96 \mathrm{~d}$ (Fig. 14B), a total downward bias of $10 \%$, or $2 \%$ more than attributable to differential mortality. In SKEW-LATE (Fig. 14C), extreme skew of spawning to late dates delayed the $\mathrm{C} 3 \rightarrow \mathrm{C} 4$ transition by $10 \mathrm{~d}$ relative to MALANGEN, with estimated $\mathrm{C} 4$ duration of $5.65 \mathrm{~d}$ (Fig. 14D), a total downward bias of $10.5 \%$ compared to the Belehradek expectation of $6.31 \mathrm{~d}$. The bias from skew timing of spawning is shortening of the apparent stage duration in both cases; the important feature is having one steep face on the spawning curve.

The Heinle graph procedure appears, despite the biases revealed by the model, to be useful for obtaining first order field estimates of stage duration, within about $10 \%$ apart from statistical variation in fitting the transition curves. Miller (in press) came to the same conclusion using a different model based on a set of field data for stage proportions. He did not consider bias from skewness of the spawning function, but did show that age distribution was nearly symmetrical by $\mathrm{C} 1$ for the univoltine population of Neocalanus plumchrus in the subarctic Pacific. Estimates of bias in our model examples apply to the expected values for the Heinle graph estimates of stage duration. Variability will be introduced to field estimates by sampling variance in proportion estimates and by spatial patchiness in the population with respect to timing of the stage progression. Miller (in press) showed for one specific case that variance of proportion estimates is a lesser source of variability than patchiness. 
28

Mar. Ecol. Prog. Ser 102: 15-34, 1993

Simulation of 'Kimmerer experiments'

Kimmerer \& McKinnon (1987) suggested a method for determination of tissue production rate in pelagic crustaceans for which a population steady state can reasonably be assumed. That assumption is clearly violated by populations of Calamus finmarchicus, but the method has been applied to them anyway by Peterson et al. (1991), who did exercise great caution in interpretation. The method is to collect a quantity of mixed copepodites by very gentle net tow, then to sieve off both the largest stage (held back by a coarse mesh) and the nauplii (which pass a fine mesh). Then a portion are preserved and a portion are incubated for a full day then preserved. Stage proportions are estmated by counting, and the molting rates for each stage are calculated according an equation from Peterson et al. (1991):

$$
\boldsymbol{M} \boldsymbol{R}_{j}=\frac{\sum_{k=1+1}^{11} \boldsymbol{N}_{k, i}-\sum_{k=1+1}^{11} \boldsymbol{N}_{k, \mathrm{~s}}}{\boldsymbol{N}_{j, \mathrm{~s}}}
$$

where $\boldsymbol{N}_{k, \mathrm{i}}$ and $\boldsymbol{N}_{k, \mathrm{~s}}$ are the estimated final and starting proportions of stages older than the stage of interest, and $N_{j, s}$ is the estimated starting proportion of that stage. Peterson et al. (1991) also point out that if growth is continuously exponential, which it generally is to a good approximation, then growth rate can be calculated for each stage as

$$
g_{j}=\ln \frac{W_{j+1}}{W_{j}} \times M R_{j}
$$

where $\boldsymbol{W}_{j}$ and $\boldsymbol{W}_{j+1}$ are the weights of the successive stages.

For convenience (and credit) we term this a 'Kimmere r experiment'. The method is attractive for its simplicity. A simple modification of MALANGEN allowed simulation of Kimmerer experiments for every day of the stage progression. At the end of each day a copy was made of the $\mathbf{A}_{j}$ and $\mathbf{D}_{j}$ vectors for $j=8,9,10$, and 11 that is, $\mathrm{C} 1$ to $\mathrm{C} 4$, equivalent to sieving out nauplii and $\mathrm{C5}$ ), and the copies were carried through the development of the following day exactly as for the originals but with no mortality (perfect experimental technique). Then molting rates for $\mathrm{C} 1$ to $\mathrm{C} 4$ were calculated from the Peterson equation. A time series of the results from a simulated Kimmerer experiment with the MALANGEN parameter set (Fig. 15A) shows that, over the intervals in which the successive stages are abundant enough for useful counting, the expecta-
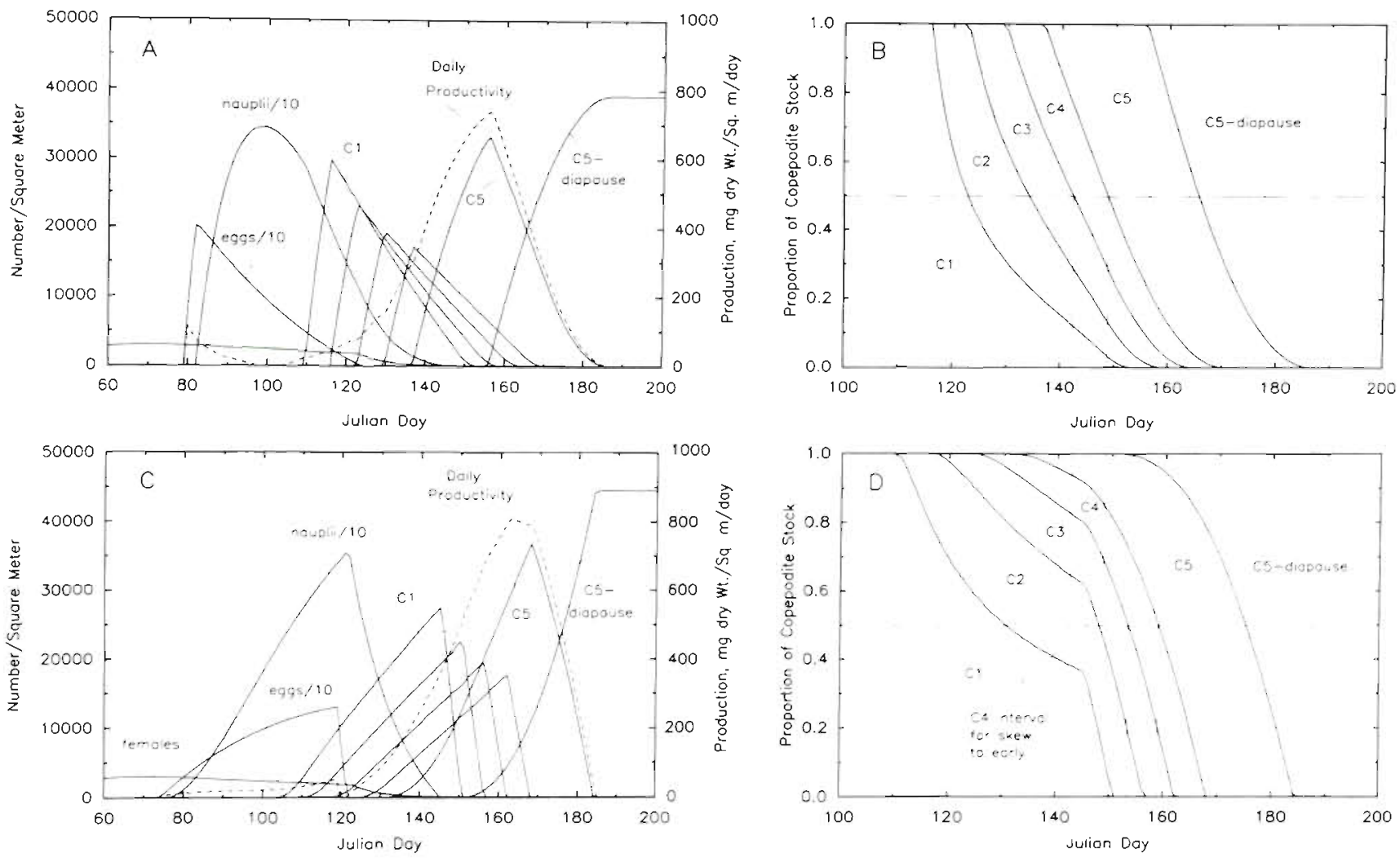

Fig. 14. (A) Output for SKEw-EARLY version of model. Skewness appears in the egg abundance curve. Total production was $11.8 \mathrm{~g}$ dry wt $\mathrm{m}^{-2}$ (B) Heine graph for SKEw-EARLY, (C) Output for SKEw-LATE version of model. Skewness appears in egg abundance curve. Total production was $13.3 \mathrm{~g} \mathrm{dry}^{\mathrm{w} t \mathrm{~m}^{-2}}$. (D) Heine graph for SKEW-LATE 

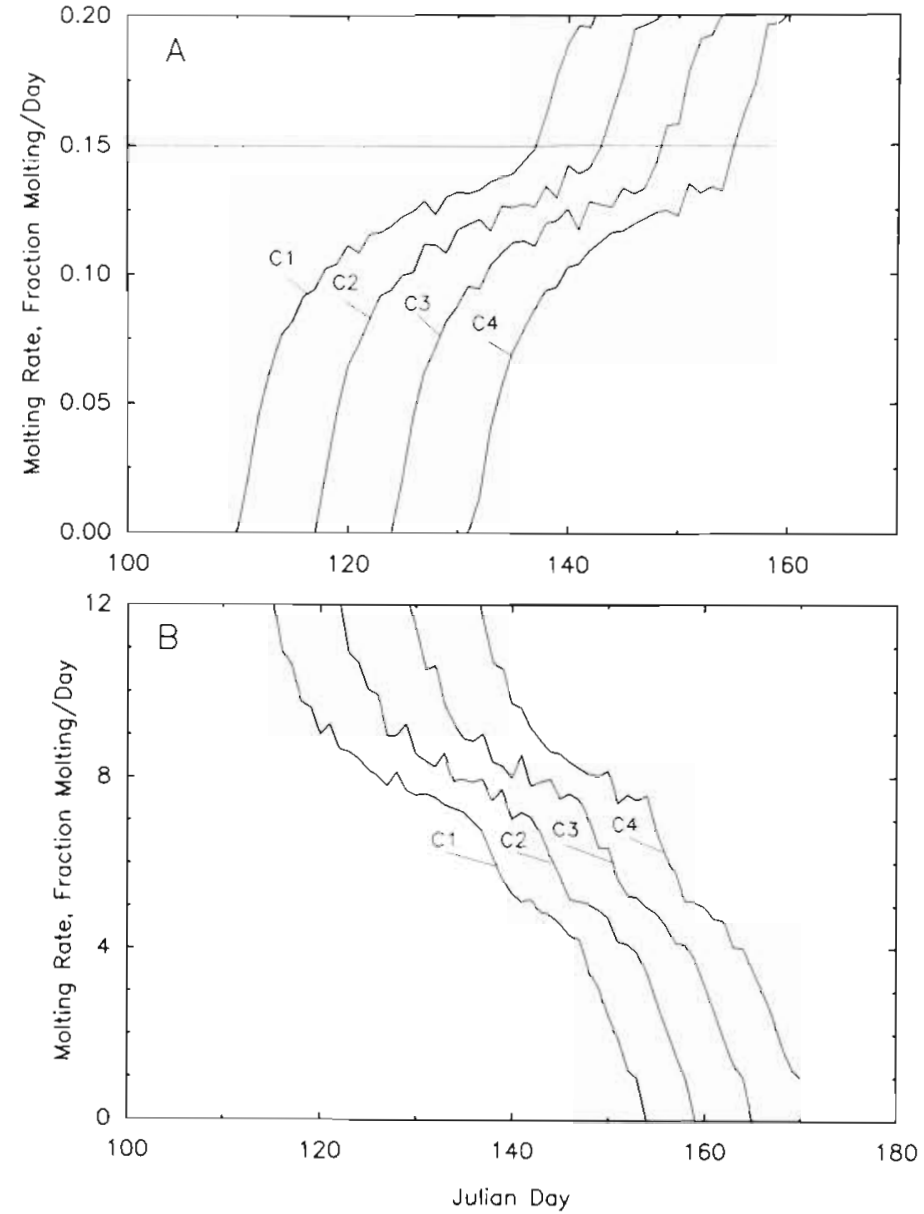

Fig. 15. (A) Molting rates, $M R_{j,}$ from a 'Kimmerer experiment' performed daly using output from MALANGEN. (B) Stage duration estimates calculated as $1 / M R_{j}$, also for MALANGEN

tions for $M R_{j}$ are not very stable, rising from about 10 to about $15 \%$ over $20 \mathrm{~d}$. If the $\boldsymbol{M} \boldsymbol{R}_{\boldsymbol{j}}$ are inverted to obtain estimates of stage duration (Miller et al. 1984), the expectations are also unstable (Fig. 15B), and give substantial overestimates of the Belehradek expectations in the parts of the graph based on substantial numbers of each stage. That is because the age-withinstage distribution favors younger individuals until well past the time of the abundance peak for each stage (Fig. 8).

Next, we conducted Kimmerer experiment simulations for the SKEW-EARLY and SKEW-LATE versions of the model. In the former, $\boldsymbol{M} \boldsymbol{R}_{\boldsymbol{j}}$ estimates were biased upward by about $5 \%$ throughout the stage progression (Fig. 16A). That is because once any individuals are old enough to molt from a stage, the age-within-stage distribution favors older individuals (thanks to the prevalence of early spawning over late spawning). In the latter, $\boldsymbol{M R}_{\boldsymbol{j}}$ were less affected (Fig. 16B), possibly because egg production in MALANGEN is already mod- erately skewed toward late dates in the spawn (Fig. 5).

We conclude that because of changing expectations and substantial possible biases, Kimmerer experiments are unlikely to give useful information about molting rate, growth rate, or stage duration for populations with a strongly progressive cohort development. Especially considering the careful experimentation required to minimize mortality from collection and sieving, and also considering the extensive counting effort required, Kimmerer experiments are not promising for evaluation of field development rates in Calanus populations. The time series of $\boldsymbol{M} \boldsymbol{R}_{\boldsymbol{j}}$ estimates has a distinctive form, suggesting that a time series of such experiments might be informative despite the biases. However, the results contain no more information than a Heinle graph which can be generated by a simpler procedure.

\section{A note on fitting of age-detailed models to data}

We have worked on the problem of fitting age-within-stage models to stage abundance data using simulated data derived from MALANGEN. In doing this the egg production function was taken to be well characterized by the data used in establishing MaLANGEN, and stage durations were taken to be strictly dependent upon temperature (as in the underlying model). The principal problem is fitting survivorship values, for which we developed a stageby-stage approach. An arbitrary survivorship for N1 $\left(\mathrm{S}_{2}\right)$ was selected, daily abundances were calculated with the model until N1 appeared and again disappeared, then the fit of the model to N1 values in a simulated sample set was evaluated by summing the squares of deviations over all sample dates. Finally, $\mathrm{S}_{2}$ was systematically varied and the model rerun for each new value until the sum of squared deviations was minimized. This was then repeated for the remaining stages. This technique reproduces the survivorships exactly when applied to data from the model at any sampling frequency.

Unfortunately, even modest sampling noise throws this simple, obvious method off course. Sampling noise was simulated by applying random Normal multipliers ranging from 0.5 to 2.0 [selected as logarithms from a $\log$ Normal distribution with $\mu=0$, and $2 \sigma=\ln (2.0)]$ to each stage at each weekly sampling (Fig. 17). Deviation from the true value in fitting of $S_{1}$ is compensated 

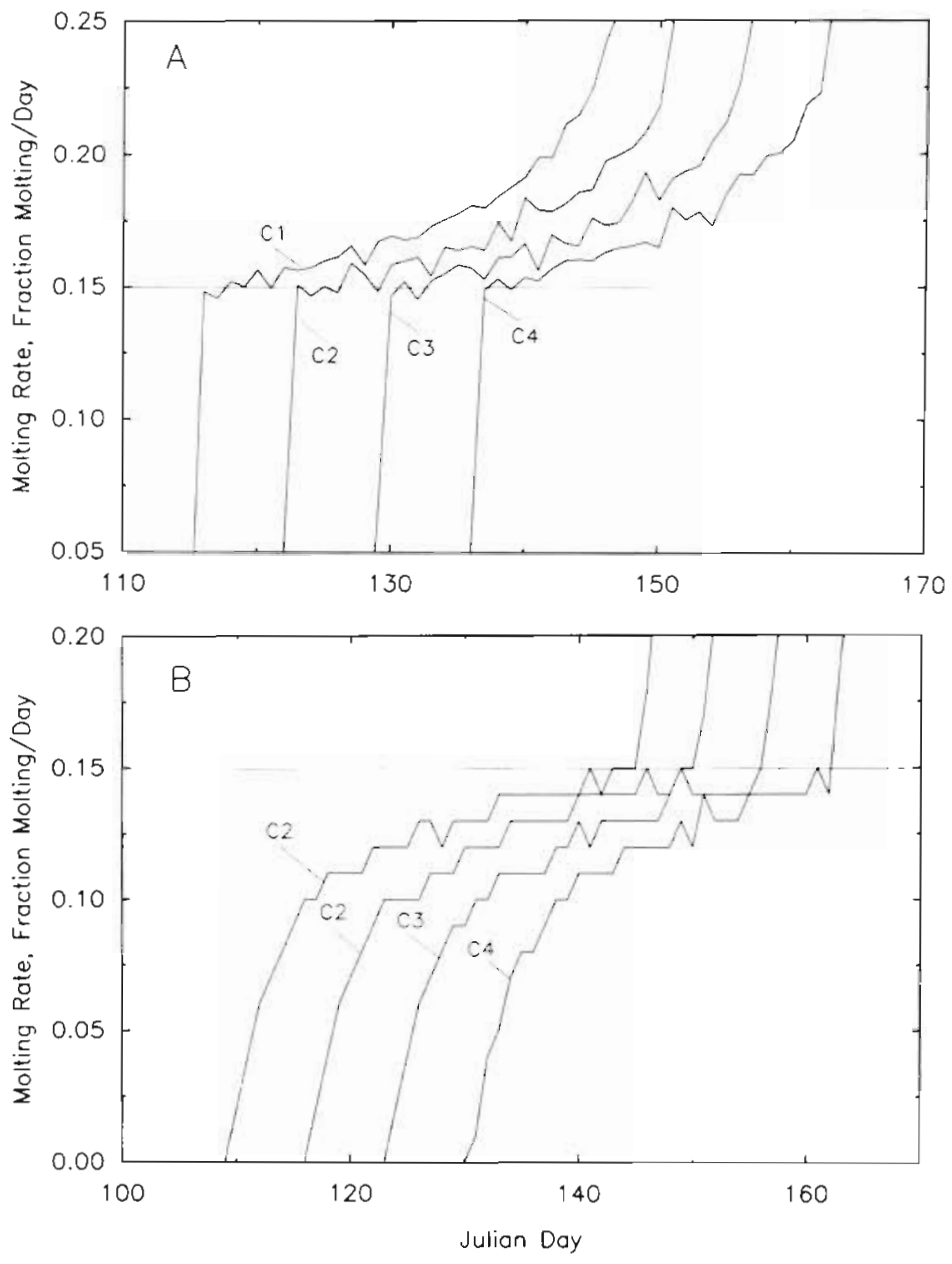

Fig. 16. Results of simulated 'Kimmerer experiment' performed on (A) SKEW-EARLY and (B) SKEW-LATE

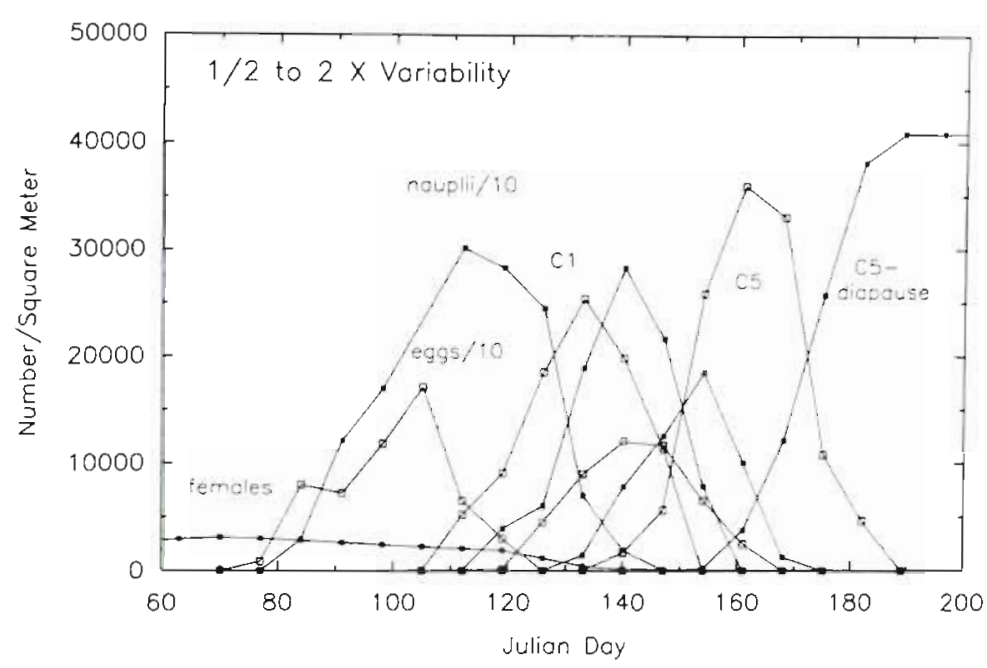

Fig. 17. Results from MALANGEN taken once each week with sampling variability applied to each stage in each sample. Variability was trom randiom, log-normal multipliers with $2 \sigma=0.5$ to 2.0 . That is, each model value was multuplied by the antilog, of a random Normal number with $\mu=0$. and $2 \sigma=\ln (2$.$) . This is a single example; every run is different$ for in fitting $S_{2}$, leading to expanding oscilla tion of later $S$ values. By V3 or N4, S, estimates at the peaks exceed 1.0 in data with this modest noise level. This general problem has been termed age propagating instability' by Wood et al. (1989) and Wood \& Nisbet (1991) If it is possible to estimate survivorship rates by fitting of age-within-stage models, it must be done by an overall fit of the survivorship set, $S_{1}$, to data for the whole generation. This might be accomplished by simulated annealing (e.g. Press et al 1986) or a related Monte Carlo technique. Given the time for individual runs of the model, this is a supercomputing problem. The methods proposed by Wood \& Nisbet (1991) may be applicable, but further study is required.

\section{DISCUSSION}

\section{Selection of mortality coefíicients}

Estimation of secondary production by application of age-within-stage models requires adoption of stage-specific mortality coefficients. This is true of some other forms of secondary production calculation as well (Fager 1973). In testing the potential of the MaLANGEN model, we have freely varied mortality to scale the stage abundance to a 'right' order of magnitude. Further thought is required as to the best rationale for doing this. Only a few studies have been conducted outlining how mortality operates in zooplankton populations (e.g. Myers \& Runge 1983). The majority of information on this issue has come from fitting various models to field population data for several marine copepod species (Matthews et al. 1978, Parslow et al. 1979, Sonntag \& Parslow 1981, Aksnes \& Magnesen 1988). From the results, we know that mortality constants for the various life stages are site and time specific, and the estimates reflect the constraints of both the sampling designs and the mathematical methods adopted. Therefore, limited insight has been gained, as yet, from these studies for sorting out the underlying mechanisms governing mortality of copepods in natural environments

Realizing the complexity of mortality estimation, some have suggested methods for estimation of secondary production of continuously reproducing populations (Huntley 
\& Boyd 1984, Kimmerer 1987, Huntley \& Lopez 1992). Those are attractive, but an intrinsic interest remains in the quantification of mortality rates. Recurring quantification of mortality is needed for understanding abundance fluctuations in the annual and biennial populations of high latitude environments. Attacks on this will depend upon what are defined as important problems. For some purposes, detailed data are required. Lynch (1983) argued that a knowledge of the shape of the mortality curves as a function of age (or stage) for natural zooplankton populations would substantially improve our understanding of the evolutionary ecology of zooplankton communities. The evolution of different life history traits is likely to depend more on the age-specific pattern than on the absolute value of mortality (Charnov \& Schaffer 1973). Although various survivorship schedules have been separated among insects (e.g. Birley 1977 and references therein), knowledge of these patterns for copepods is very limited. We have only begun to explore the consequences of different mortality schedules using our age-within-stage models. Data from Tande (1988) and Pedersen \& Tande (1992) suggest that survivorship schedules in Calanus differ between constant and continuously increasing temperatures. The simulations showed that such differences in pattern are critical to annual survival and stock production. Thus, detailed studies of the response of mortality to schedules of habitat variation are in order. Exactly how to accomplish this for field populations remains to be invented.

If, on the other hand, one is primarily interested in year-to-year stock fluctuations, simpler overall estimates might suffice. We could easily simulate constant final survivorship with a huge range of stage-specific survivorship patterns (Fig. 13). Perhaps interannual variation in survivorship could be characterized from recurring studies of the abundance of resting stocks in autumn. Estimation in this case could be greatly aided by detailed acoustic or optical counting techniques, both of which are best suited to the nearly monotypic assemblages characteristic of Calanus resting stocks.

\section{On fitting of the model to data}

The key data for development of a model of this type are the egg production experiments from which the egg production function is described. For Malangen Fjord we have the advantage of repeated egg production determinations for Calanus finmarchicus throughout the adult phase of $\mathrm{G}_{0}$ (Diel \& Tande 1992). Application of age-detailed models to stocks in other places will require appropriate, local egg production studies. Data should include both daily egg production per capita and recurring estimates of female abundance. In our model the female abundance essentially was guessed based on reasonable density and maturation timing for diapausing C5. Realism of the models can be improved with direct data on female abundance.

A more sophisticated study of the fitting of the model to simulated sampling data and to real data is in order. We only began a study of the former, and did not try to fit the model to actual data. On the whole, field data in the literature are weak on sampling of some part of the life history. Frequently, egg or naupliar data are missing altogether. In the best studies (e.g. Marshall et al. 1934, Aksnes \& Magnesen 1983), nauplii and early copepodite stages are underestimated relative to later copepodite stages; the integrals of time-abundance curves for younger stages are much less than for later copepodites. The differences are several-fold, much larger than can be explained by longer durations of the later stages. For nets towed from deep to shallow, the source of this bias apparently is interaction between the deepening vertical distributions of successive stages and net clogging The younger, shallower-living stages are undersampled relative to older ones because the filtration efficiency drops before the rising net reaches them. Marshall et al. (1934) stated the argument as follows

$\therefore$... at this time [spring 1933] diatoms were very abundant. These would clog the meshes of the net and so reduce the amount of water filtered, particularly in the upper layers where the eggs and nauplii live.'

The same explanation must apply to the data of Grønvik \& Hopkins (1984) for Metridia longa in Balsfjorden. They show progressively greater abundance from $\mathrm{C} 1$ through $\mathrm{C} 3$ and a further jump at C5. Again, only a modest fraction of the apparent increase is likely due to lengthening stage durations. Daytime vertical distributions in $M$. longa deepen progressively with stage of development.

In our opinion, this problem of sampling bias is likely to be the greatest obstacle to estimation of field mortality by fitting of models. There is no obvious way to compensate for the differentials in sampling bias. We suggest that thought be given to obtaining samples unbiased by clogging. Perhaps a version of Murphy \& Clutter's (1972) plankton purse seine could be developed to capture early stages near the surface despite clogging. If it catches nauplii, it will also catch massive quantities of diatoms (including the glutinous Phaeocystis pouchetti). Thus, copepod counts will be difficult to make in the resulting samples. Another scheme might be very short tows with a multiple net, monitoring filtration on deck with flowmeters well back in the successive bags of mesh. 

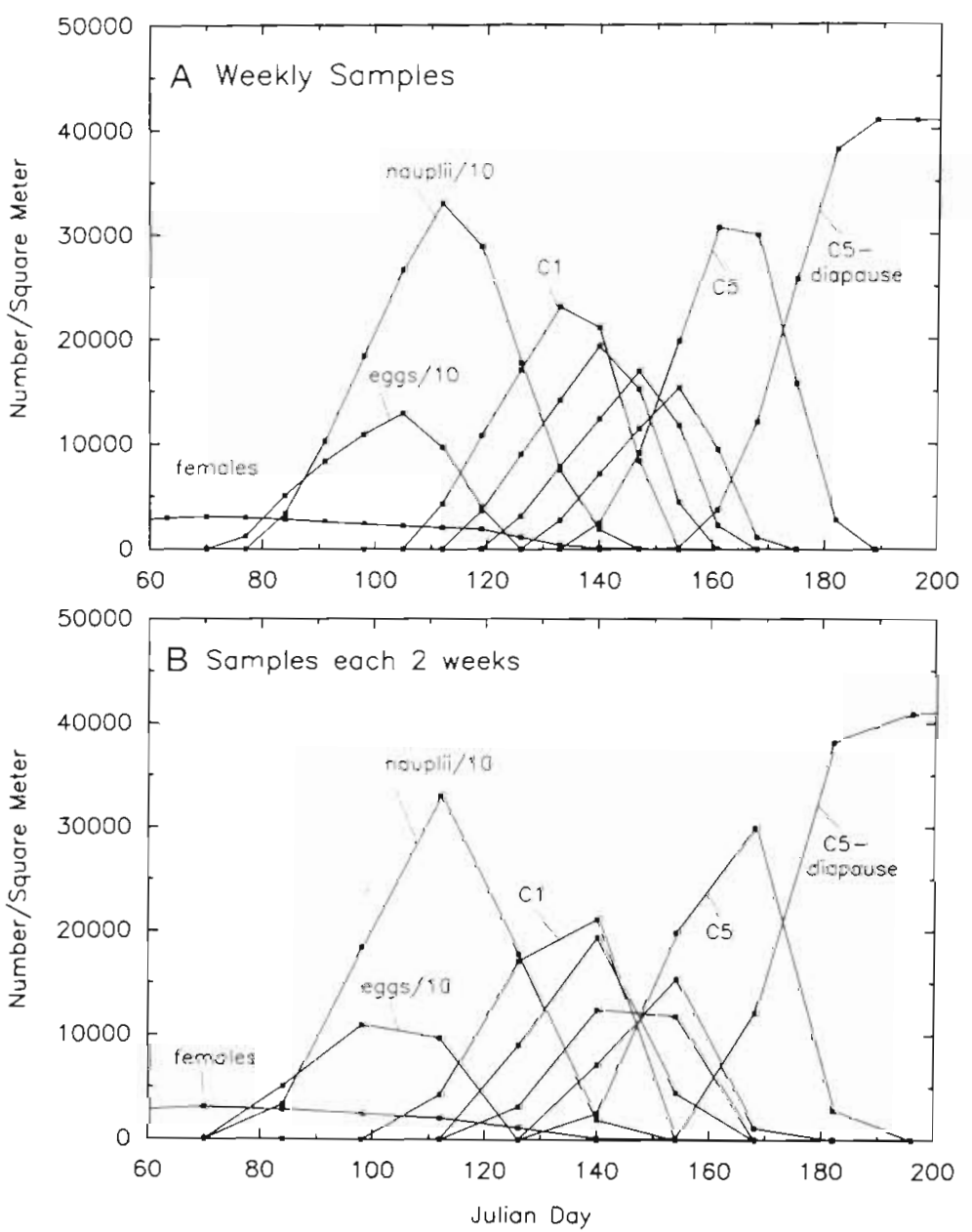

Fig. 18. Comparison of results from MALANGEN (without sampling variability) for (A) weekly and (B) biweekly sampling

Nets would be changed when filtration efficiency dropped below a criterion. This will work if clogging is not nearly instantaneous. Large capacity pumps (e.g Taggart \& Leggett 1984) are another possibility, if it can be shown that older stages are not better than younger ones at avoiding the intake. For either pumps or multiple nets, sorting of copepods from masses of diatoms will be entailed in counting the samples. This is an unpleasant but not an insuperable problem.

Fitting of age-within-stage models to real data obviously will require sampling results of high enough frequency to represent the stage progression adequately. Just from the visual impression of plots of simulations based on MALANGEN, weekly sampling (Fig 18A) seems to be sufficient to represent most aspects of the stock progression. With sampling only every $2 \mathrm{wk}$ (Fig. 18B), considerable resolution is lost. Specifically, even without field variability in sampling results, the timing of peaks is obscured, with several stages reaching their apparent peaks on the same sampling date. This problem will be more severe for warmer habitats than for colder ones. For example, Marshall et al. (1934) found the peaks of $\mathrm{C} 1, \mathrm{C} 2$ and $\mathrm{C} 3$ in $\mathrm{G}_{1}$ to have almost identical timing in the relatively warm Loch Striven habitat. When this occurs, it will make selection of reasonable parameters for a fit quite difficult. Extended analysis is needed of the interactive effects of sampling frequency, habitat temperature, and short-term sampling variability on parameter estimates.

\section{Estimation of stage duration}

We conclude from our simulations that stage duration can be estimated with reasonable precision by examining the temporal progression of fractional abundances of the stages, by developing data for a 'Heinle graph'. There is significant bias from confounding of the stage duration with differential mortality rates between the stages, and a small additional bias (in some cases compensating) from skewness in the timing of egg production. Our modelling of seeming worst-case differentials and skewness showed the Heinle graph estimates for duration of $\mathrm{C} 4$ to be biased by no more than $10 \%$. Imprecision from sampling variability and from upstream-downstream variation in population development timing will likely be larger than this bias. At a minimum, estimates from this approach will allow comparisons of development rates between sites and between years. An application by Durbin \& Durbin (unpubl.) to the $G_{1}$ cohort of Calanus finmarchicus in 2 yr showed a large difference in stage duration between years. They attributed this to a difference in food availability. While food availability plays no role in our model, the model shows that the difference is not likely to arise from bias in the stage duration estimate.

Our simulations show that molting rates (and stage durations estimated from molting rates) measured by incubation experiments will not have a stable expectation for a cohort developing in the manner of the $G_{1}$ generation of Calanus finmarchicus. We are convinced that, for population cycles of the Calanus type, 'Kimmerer experiments' are not worth the investment of time and labor they require. This conclusion should not be extended to the roughly steady-state populations for which Kimmerer \& McKinnon (1987) developed the technique. 
Acknowledgements. We thank François Carlotti and an anonymous reviewer for very helpful comments on this paper Support for C. B. Miller during this modelling study came from the U.S. National Science Foundation (OCE-9012295). $K$. Tande thanks The Research Council of Norway, NFFR Division, for a stipend during his sabbatical stay at Oregon State Unıversity

\section{LITERATURE CITED}

Aksnes, D. L., Magnesen, T (1983). Distribution, development, and production of Calanus finmarchicus (Gunnerus) in Lindåspollene, Western Norway, 1979. Sarsia 68: $195-208$

Aksnes, D. L., Magnesen, T. (1988). A population dynamics approach to the estimation of production of four calanoid copepods in Lindåspollene, western Norway. Mar. Ecol. Prog. Ser. 45: 57-68

Birley, M. (1977). The estimation of insect density and instar survivorship functions from census data. J. Anim. Ecol. 46: $497-510$

Buckley, L. J., Lough, R. G. (1987). Recent growth, biochemical composition, and prey field of larval haddock (Melanogrammus aeglefinus) and Atlantic cod (Gadus morhua) on Georges Bank. Can. J. Fish. Aquat. Sci. 44: $14-25$

Carlotti, F., Krause, M., Radach, G. (1993). Growth and development of Calanus finmarchicus related to the influence of temperature: experimental results and conceptual model. Limnol. Oceanogr. (in press)

Carlotti, F., Nival, P. (1992). Model of copepod growth and development: moulting and mortality in relation to physiological processes during an individual moult cycle. Mar. Ecol. Prog. Ser. 84: 219-233

Carlotti, F., Nival, S. (1992). Moulting and mortality rates of copepods related to age within stage: experimental results. Mar. Ecol. Prog. Ser. 84: 235-243

Carlotti, F, Sciandra, A. (1989). Population dynamics model of Euterpina acutifrons (Copepoda: Harpacticoida) coupling individual growth and larval development. Mar Ecol. Prog. Ser. 84: 235-243

Caswell, H. (1989). Matrix population models. Sinauer, Sunderland, MA

Charnov, E. I., Schaffer, W. M. (1973). Life-history consequences of natural selection: Cole's results revisited. Am. Nat. 107: 791-793

Corkett, C. J., McLaren, I. A., Sevigny, J.-M. (1986). The rearing of calanoid copepods Calanus finmarchicus (Gunnerus), C. glacialis Jaschnov and C. hyperboreus Kroyer with comment on the equiproportional rule. Nat. Mus. Can, Syllogeus Ser. 58: 539-551

Davis, C. S. (1984). Interaction of a copepod population with the mean circulation on Georges Bank. J. mar. Res. 42: $573-590$

Diel, S., Tande, K. S. (1992). Does the spawning of Calanus finmarchicus in high latitudes follow a reproducible pattern? Mar. Biol. 113: 21-31

Ellertsen, B., Fossum, P., Solemdal, P., Sundby, S. (1989). Relations between temperature and survival of eggs and first feeding larvae of the Arcto-Norwegian Cod (Gadus morhua). Rapp. P.-v. Réun. Cons. int. Explor. Mer 191: $209-219$

Fager, E. W. (1973). Estimation of mortality coefficients from field samples of zooplankton. Limnol. Oceanogr 18: $297-301$
Gronvik, S., Hopkins, C. C. E. (1984). Ecological investigations of the zooplankton community of Balsfjorden, northern Norway: generation cycle, seasonal vertical distribution, and seasonal variations in body weight and carbon and nitrogen content of the copepod Metrida longa (Lubbock). J. exp. mar. Biol. Ecol. 80: 93-107

Hairston, N. G. Jr, Twombly, S. (1985). Obtaining life table data from cohort analyses: a critique of current methods. Limnol. Oceanogr. 30: 886-893

Heinle, D. (1966). Production of a calanoid copepod, Acartia tonsa, in the Patuxent River estuary. Chesapeake Sci. 7: 59-74

Huntley, M. E., Boyd, C. (1984). Food-limited growth of marine zooplankton. Am. Nat. 124: 455-478

Huntley, M. E., Lopez, M. D. G. (1992). Temperaturedependent production of marine copepods: a global synthesis. Am. Nat. 140(2): 201-242

Johnson, J. K. (1981). Population dynamics and cohort persistence of Acartia californiensis (Copepoda: Calanoida) in Yaquina Bay, Oregon. Ph.D. thesis, Oregon State University, Corvallis

Kane, J. (1984). The feeding habits of co-occurring cod and haddock larvae from Georges Bank. Mar. Ecol. Prog. Ser. 16: $9-20$

Kimmerer, W. J. (1987). The theory of secondary production calculations for continuously reproducing populations. Limnol. Oceanogr. 32: 1-13

Kimmerer, W. J., McKinnon, A. D. (1987). Growth, mortality and secondary production of the copepod Acartia tranteri in Westernport Bay, Australia. Limnol. Oceanogr. 32 : $14-28$

Landry, M. R. (1983). The development of marine calanoid copepods with comment on the isochronal rule. Limnol. Oceanogr. 28: 614-624

Lynch, M. (1983). Estimation of size-specific mortality rates in zooplankton populations by periodic sampling. Limnol. Oceanogr. 28: 533-545

Marshall, S. M., Nicholls, A. G., Orr, A. P. (1934). On the biology of Calanus finmarchicus. $V$ Distribution, size, weight and chemical composition in Loch Striven in 1933, and their relation to phytoplankton. J. mar. biol. Ass. U.K. 19: $793-827$

Matthews, J. B. L., Hestad, L., Bakke, J. L. W. (1978). Ecological studies in Korsfjorden, west Norway. The generations and stocks of Calanus hyperboreus and C. finmarchicus in 1971-1977. Oceanol. Acta 1: 277-284

McLaren, I. A. (1978). Generation lengths of some temperate marine copepods: estimation, prediction, and implications. J. Fish. Res. Bd Can. 35: 1330-1342

McLaren, I. A., Corkett, C. J. (1986). Life cycles and production of two copepods on the Scotian shelf, eastern Canada. Nat. Mus. Can. Syllogeus Ser. 58: 362-367

Miller, C. B. (in press). Development of large copepods during spring in the Gulf of Alaska. Prog. Oceanogr

Miller, C. B., Cowles, T. J., Wiebe, P. H., Copley, N. J., Grigg, H. (1991). Phenology in Calanus finmarchicus; hypotheses about control mechanisms. Mar. Ecol. Prog. Ser. 72: $79-91$

Miller, C. B., Huntley, M. E., Brooks, E. R. (1984). Postcollection molting rates of planktonic marine copepods: measurement, applications, problems. Limnol. Oceanogr. 29: $1274-1289$

Miller, C. B., Nielsen, R. D. (1988). Development and growth of large, calanid copepods in the ocean[ic] subarctic Pacific, May 1984. Prog. Oceanogr. 20: 275-292

Murphy, G. I., Clutter, R. I. (1972). Sampling anchovy larvae with a plankton purse seine. Fish. Bull. U.S. 70: 789-798 
Myers, R. A., Runge, J. A. (1983). Predictions of seasonal natural mortality rates in a copepod population using lifehistory theory. Mar. Ecol. Prog. Ser. 11. 189-194

Myers, R. A., Runge, J. A. (1986). Temperature-dependent changes in copepod adult size: an evolutionary theory. Nat. Mus. Can. Syllogeus Ser. No. 58: 374-376

Nielsen, T G., Richardson, K. (1989) Food chain structure of the North Sea plankton communities: seasonal variations of the role of the microbial loop. Mar. Ecol. Prog. Ser. 56: $75-87$

Parslow, J., Sonntag, N., Matthews, J. B. L. (1979). Technıque of systems identification applied to estımating copepod population parameters. J. Plankton Res. 1: 137-151

Pedersen, G., Tande, K. S (1992). Physiological plasticity to temperature in Calanus finmarchicus. Reality or artefact? J. exp. mar Biol. Ecol. 155: 183-197

Peterson, W T (1986). Development, growth, and survivorship of the copepod Calanus marshallae in the laboratory. Mar. Ecol. Prog. Ser. 29:61-72

Peterson, W. T., Painting, S. J (1990). Developmental rates of the copepods Calanus australis and Calanoides carinatus in the laboratory, with discussion of methods used for calculation of development time. J. Plankton Res. 12: 283-293

Peterson, W. T., Tiselius, P., Kiørboe, T (1991). Copepod egg production, moulting and growth rates, and secondary production, in the Skagerrak in August 1988. J. Plankton Res. 13: 131-154

Press, W. H., Flannery, B. P., Teukolsky, S. A., Vetterling, W. T (1986). Numerical recipes; the art of scientıfic computing. Cambridge Univ. Press, Cambridge

Runge, J. A. (1985). Egg production rates of Calanus fmmarchicus in the sea of Nova Scotia. Arch. Hydrobiol. Beih. Ergebn. Limnol. 21:33-40

Sciandra, A. (1986). Study and modelling of development of Euterpina acutifrons (Copepoda, Harpacticoida). J. Plankton Res. 8: 1149-1162

Slagstad, D. (1981). Modelung and simulation of physiology and population dynames of copepods. Effects of physical and

This article was presented by B. and E. Sherr, Corvallis, Oregon, USA biological parameters. Model. Ident. Control 2: 119-162

Slaystad, D., Tande, K. (1990). Growth and production dynamics of Calanus glacialis in an arctic food web. Mar. Ecol. Prog. Ser. 63: 189-199

Sonntag, v., Parslow, J. (1981). Technique of systems identification applied to estımating copepod production. J. Plankton Res. 3: 461-473

Taggart, C. T., Leggett, W. C. (1984). Efficiency of largevolume plankton pumps, and evaluation of a design sultable for deployment from smail boats. Can. J. Fish. Aquat. Sci. 41: 1428-1435

Tande, K. S. (1988). Aspects of developmental and mortality rates in Calanus finmarchicus related to equiproportional development. Mar. Ecol. Prog. Ser. 44: 51-58

Tande, K. S. (1991). Calanus in north Norweglan fjords and in the Barents Sea. Polar Res. 10(2): 389-407

Tande, K. S., Slagstad, D. (1992). Regional and interannual variations in biomass and productivity of the marine copepod, Calanus finmarchicus, in subarctic environments. Oceanol. Acta 15: 309-321

U.S. GLOBEC (1992). Northwest Atlantic implementation plan. U.S. Global Ocean Ecosystems Dynamics, Report No. 6. Davis, CA

Vidal, J. (1981). Physloecology of zooplankton. I. Effects of phytoplankton concentration, temperature, and body size on the growth rate of Calanus pacificus and Pseudocalanus sp. Mar. Biol. 56: 111-134

Walsh, J. J., Whitledge, T E., O'Reilly, J E., Phoel, W. C., Draxler, A. F. (1987). Nitrogen cycling on Georges Bank and the New York shelf: a comparison between well-mixed and seasonally stratıfied waters. In: Backus, R. H. (ed.) Georges Bank. The MIT Press, Cambridge, p. 234-246

Wood, S. N., Blythe, S. P., Gurney, W. S., Nisbet, R. M. (1989). Instabiluty in mortality estimation schemes related to stage structure population models. IMA J. Math. Apl. Med. Biol. 6: $47-68$

Wood, S. N., Nisbet, R. M. (1991). Estimation of mortality rates in stage-structured populations. Lecture notes in biomathematics, 90 . Springer-Verlag. Berlin

Manuscript first recelved: May 3, 1993

Revised version accepted: July 27, 1993 